\title{
Do investors and entrepreneurs match? - Evidence from The Netherlands and Sweden
}

\author{
Friedemann Polzin $^{\mathrm{a}, *}$, Mark Sanders ${ }^{\mathrm{a}}$, Ulrika Stavlöt ${ }^{\mathrm{b}}$ \\ a Utrecht University School of Economics (USE) and Sustainable Finance Lab (SFL), Kriekenpitplein 21-22, 3584, EC, Utrecht, The Netherlands \\ ${ }^{\mathrm{b}}$ Forum for Reforms, Entrepreneurship and Sustainability (FORES), Kungsbroplan 2, 11227 Stockholm, Sweden
}

\section{A R T I C L E I N F O}

\section{JEL classification:}

O31

$\mathrm{O} 38$

G24

G28

\section{Keywords:}

Matching

Investors

Entrepreneurs

Risk perception

VC business model

Green tech

\begin{abstract}
A B S T R A C T
Entrepreneurs and investors face challenges in the 'thin market' for early stage entrepreneurial finance. Improving this situation has been a priority of policy makers for at least a decade, however, the challenges in this matching process are still poorly understood. Theory suggests that matching problems may originate in different perceptions in areas such as evaluation criteria, risk and risk management by investors and entrepreneurs. To find a good match it seems essential to understand what is important to your counterpart. Based on a mixed methods approach using data collected in semi-structured interviews and a survey with both entrepreneurs and investors mostly active in green tech innovation, this study systematically analyses where their perceptions deviate and where frictions in the matching process may occur. We find that a mismatch exists in the perception of risk, the importance attached to risk, the search channels used to find a potential partner and the evaluation criteria applied in evaluating a proposition (i.e., exit, innovativeness, capabilities of teams). This paper suggests that increasing market transparency and creating a mutual understanding of the investment process will prevent potentially damaging perception misalignment from arising in the first place.
\end{abstract}

\section{Introduction}

This paper explores how financiers and entrepreneurs approach matching in thin markets for venture capital (VC). There is growing interest in the interplay between finance and entrepreneurship (Mina et al., 2013; Polzin, 2017; Stucki, 2014). High-impact entrepreneurship is an important driver in any transformation process (Cohen and Winn, 2007; Marcus et al., 2013; Wüstenhagen and Wuebker, 2011). However, young, high-impact entrepreneurial firms are also the most finance-constrained (Demirel and Parris, 2015; Giudici and Paleari, 2000; Mina et al., 2013; Stucki, 2014). It has been argued that this constraint does not lie in a shortage of funds or ideas. Indeed, venture capitalists (VCs) finance potential breakthrough innovations, and funding for disruptive technologies is not constrained on the supply side (Nightingale et al., 2009). Also, there is seemingly no shortage of entrepreneurs with potentially profitable new business ideas.

The bottleneck is in the matching process: entrepreneurs struggle to find and then secure investment, whereas investors struggle to identify and establish projects that are investment grade (Bertoni et al., 2015b; Nightingale et al., 2009). Despite abundant funds and ideas, however, evaluating the ideas and negotiating a deal requires a lot of specialised knowledge and time-consuming exchange and verification of information. Both sides of the market face high search and transaction costs to facilitate a successful match. The problem is exacerbated by the fact that the venture capital market is highly compartmentalised (Nightingale et al., 2009). The matching process in venture capital can therefore be characterised as a 'thin market', with only a few relevant and active investors for any entrepreneur and a limited relevant group of entrepreneurs for any investor (Bertoni et al., 2015b; Hall et al., 2016; Hopkins et al., 2013; Nightingale et al., 2009).

Scholars have modelled the matching between investors and entrepreneurs as a two-staged process, in which entrepreneurs look for investors first and then investors evaluate the entrepreneurs who find them. From these models, one can derive propositions about selection mechanisms based on the ventures' characteristics (Bengtsson and Hsu, 2015; Bertoni et al., 2015b; Eckhardt et al., 2006; Sørensen, 2007). In this paper, we build on that literature by adding the possible effect of entrepreneur and investor perceptions on the matching process. To the best of our knowledge, that element has hitherto been missing in the analysis of actual deal flow and completed as well as aborted investments.

As a starting point, we assume that to effectively and efficiently find a match in a 'thin market' it helps if investors and entrepreneurs understand each other's motivation, position, concerns, evaluation criteria

\footnotetext{
* Corresponding author.

E-mail address: f.polzin@uu.nl (F. Polzin).
} 
and priorities (Bengtsson and Hsu, 2015; Franke et al., 2006; Ruef et al., 2003). If entrepreneurs search for investors using different channels from the ones investors use, if they subsequently pitch information that investors do not value, or if investors demand information or concessions that entrepreneurs are not willing to give, then finding a match will be more difficult. We therefore hypothesise that a better understanding of the other side's position reduces the ex-ante search costs and facilitates the ex-post matching.

To test that hypothesis empirically and in general, however, requires a very complex data collection effort. ${ }^{1}$ In this paper, we therefore take a more modest and practical approach in our data collection and we can only investigate how investors and entrepreneurs perceive critical aspects and stages in the matching process. As differences in perception are a necessary condition for the main hypothesis to hold, testing if that condition is met in our data is a useful first step. To ensure that differences in perceptions are not due to differences in culture or industry as well as for practical reasons, we use data that was collected on green tech entrepreneurs and investors in Sweden and The Netherlands. This choice was motivated on the one hand because a shortage of early stage venture finance seems particularly acute in the green technology sector (Foxon et al., 2008; Iyer et al., 2015; Kenney and Hargadon, 2012; Mazzucato, 2013; van den Bergh, 2013). On the other hand, in this capital and knowledge intensive sector, information asymmetries and perception misalignments are more likely. For example Sanders et al. (2013) interviewed Dutch VCs on the potential of investing in capital and knowledge intensive carbon capture and storage, concluding that misaligned perceptions of especially policy risk proved hard to manage.

Our contribution is that we find significant differences in the perception of risks, the choice of search channel and the evaluation criteria for potential deals (e.g., exit, innovativeness, and capabilities of teams). This result implies that misaligned perceptions are a potential problem, even if our data does not allow us to test the hypothesis that such misalignments cause inefficiencies in matching. More research is therefore justified. But as an ounce of prevention is better than a pound of cure, perhaps our results should also motivate policies to prevent and reduce misaligned perceptions in venture capital markets.

The remainder of this paper is structured as follows. Section 2 reviews the diverse body of entrepreneurial finance literature relating both to the perception of the investment process from an entrepreneur's and investor's point of view. Section 3 presents the mixed methods approach consisting of semi-structured interviews and a fully structured survey. Section 4 then integrates the qualitative and quantitative results and relates these to existing theory. Concluding remarks and implications of this study for policy makers are presented in Section 5.

\section{Theoretical background}

\subsection{Thin markets for entrepreneurial finance}

Early work on financing of young, innovative companies points towards the existence of a funding gap (also known as the "valley of death') that relates both to the nature of innovation and the financing of start-ups (Cassar, 2004; Cressy, 2002; Giudici and Paleari, 2000; Hall, 2002). Uncertainty, limited appropriability of the returns, lack of collateral and asymmetric information make early stage ventures unsuitable for bank finance (Berger and Udell, 2006, 2003). As such, more

\footnotetext{
${ }^{1}$ One would need to collect information on the ex-ante perceptions in pairs of investors and entrepreneurs that have attempted to match across the many compartments in the venture capital industry. Even if one would limit the study to a specific industry, it is practically impossible to collect such an ideal dataset. One would have to set up a cohort study in which all nascent entrepreneurs are followed and all active investors have been surveyed on their perceptions before some of the entrepreneurs approach them. Only then can one properly establish the effect of ex-ante perception misalignment on ex-post matching probabilities, controlling for the many things that also affect the latter.
}

specialised investors emerged to fill this gap. They have developed advanced methods to search, select and monitor potential investment targets in the early/seed stage (Gompers, 1995; Gompers and Lerner, 2001). These investors also add professional services such as networking and managerial advice to support start-up development (Gorman and Sahlman, 1989; Hellmann and Puri, 2002, 2000; Hsu, 2006; Sahlman, 1990). However, this costly, time consuming and knowledge intensive process can only be conducted by a limited number of highly skilled and specialised investors evaluating a limited number of prospective investments. Due to the high degree of diversity in prospective ventures and the intense, long-term commitments involved, the model of the venture capitalist is hard to scale up.

This led to the notion of 'thin markets' for venture finance (Bertoni et al., 2015b; Mina et al., 2013; Nightingale et al., 2009). 'Thin markets occur when small numbers of high potential firms and small numbers of investors with the skills to help them grow find it difficult to find one another without incurring unacceptable transaction and/or search costs' (Nightingale et al., 2009, p. 21). These markets cannot be characterised simply by pointing towards a demand problem (i.e., low quality of firms) or supply problem (i.e., not enough available funds). Instead the demand problem is that entrepreneurs are unable to credibly and reliably signal the quality of their projects, and the supply problem is that investors struggle to tailor finance to the specific and rapidly changing needs of the venture. Nightingale et al. (2009) assert that 'because thin markets make it difficult for the supply and demand for finance to match they reduce overall levels of investment'. Standardization and repeated interaction between supply and demand characterising 'thick' markets would allow for the emergence of an ecosystem for early stage finance, but this is absent or dysfunctional in most countries. Scholars consequently diagnosed the 'valley of death' phenomenon in entrepreneurial finance as a coordination problem and a matching problem (Bertoni et al., 2015b; Mina et al., 2013; Nightingale et al., 2009).

In general, VC markets in Europe are less developed than their US counterpart, arguably because of more conservative institutional investors and strong bank-based financial systems in many European countries (Bertoni et al., 2015a; Hirsch-Kreinsen, 2011). Moreover, European markets are also nationally compartmentalised. In response to the thinner supply side, a much smaller share of early stage ventures in Europe actively seek VCs to finance firm growth (Bertoni et al., 2015b, 2011; Colombo and Grilli, 2010; Peneder, 2010). Nevertheless, venture capital investors in Europe claim that there is no shortage of funds for good ideas, thus the 'thin markets' problem is probably larger in Europe than it is in the United States (Nightingale et al., 2009). A smaller number of investors typically chases after a smaller pool of investment grade ventures. Hence, we may expect problems in the matching process to be most pronounced there.

\subsection{Signalling and matching of investors and entrepreneurs}

To analyse the matching process between entrepreneurs and investors we can build on a 2-stage matching process model (Bertoni et al., 2015b; Eckhardt et al., 2006; Sørensen, 2007). In the first stage, entrepreneurs decide to go on the market and look for venture capital (self-selection). In the second stage, investors screen the potential candidates, select the best (sorting) and decide whether to invest. The motivation for entrepreneurs and investors to search is different from the outset. Eckhardt et al. (2006) found that entrepreneurs base their decision to look for venture capital on competition, market growth and employment growth, while investors base their funding decisions on indicators of venture growth, such as degree of organising activities, marketing activities and the level of sales. This implies that there is ample room for strategic search behaviour and a need for verification. Both stages are therefore costly in terms of search effort being spent on both sides. A way for entrepreneurs and investors to reduce these search costs is to signal relevant information to potential counterparties in the market. For instance, investors will limit the sectors in which they are 
active and entrepreneurs can signal the quality of their venture with a sound business plan in line with the signalling theory as originally developed for labour market matching processes and successfully applied to corporate finance (Connelly et al., 2011; Spence, 1973).

In the context of venture finance, a signal helps both investors and entrepreneurs screen for suitable prospects. Hence the screening, selection and matching process will be heavily influenced by the perception of different signals by entrepreneurs and investors and by the perception of how the other side will interpret the signal that is sent. In the entrepreneurial finance literature, there is some evidence that characteristics that can objectively be signalled, like composition of the founding team, patents, R\&D subsidies and company characteristics, have an impact (Audretsch et al., 2012; Busenitz et al., 2005; Kleer, 2010). Scholars also find that objective and subjective quality criteria, and the perceptions of both investors and entrepreneurs of each other, matter in finding a match (Eckhardt et al., 2006; Riding and Short, 1987; Sørensen, 2007). From the available evidence we can even conclude that aligned perceptions between entrepreneurs and investors help the matching process (Bengtsson and Hsu, 2015; Franke et al., 2006; Murnieks et al., 2011; Ruef et al., 2003). ${ }^{2}$

The theoretical developments in both the signalling and the matching literature suggest we can therefore hypothesise that aligned perceptions are an important precondition for efficient matching in the thin market for VC finance (Bengtsson and Hsu, 2015; Bertoni et al., 2015b; Connelly et al., 2011; Franke et al., 2006). Moreover, such alignment is probably most important in the more critical stages of the matching process which include channels of contact, pitching and due diligence as well as perceptions of risk and risk management (Bertoni et al., 2015b; Eckhardt et al., 2006; Sørensen, 2007). To test the full hypothesis properly, however, would require collecting data on the perceptions of venture capitalists and entrepreneurs before they engage in searching and then show that the lack of aligned perceptions going into the search is systematically correlated with the probability of finding and successfully making a match. That is a very complicated and costly exercise. So instead we first collected data that can help us establish if the problem is real. As a first step, we propose to test in a sample of entrepreneurs and venture capitalists if perceptions are indeed misaligned. If the answer to that is 'no' we can conclude that aligning perceptions will not help improving the matching in these VC markets. If it is 'yes' then more research and perhaps experiments in policy can be justified.

Eckhardt et al. (2006) and others have typically identified two stages in the matching process: the searching and the evaluation and matching stage. We have split the latter into pitching and due diligence, in which objective information is exchanged and validated, and the risk and management stage, in which differences of opinion and assessments of risk may persist but need to be explicated.

\subsubsection{Searching: leveraging social networks to generate deal flow}

To generate deal flow both investors and entrepreneurs first need to establish contact. A number of channels exist to establish a relationship, such as fairs and conferences, family and friends, existing business relations or more structured incubator programmes (Gompers and Lerner, 2001). The choice of search channel is important and, to make this choice, both parties typically use soft information (Berger et al., 2005; Petersen and Rajan, 2002; Stein, 2002). Social networks convey valuable information in this respect (Fried and Hisrich, 1994; Granovetter, 1973). We propose that a substantially different ranking of importance of these search channels by investors and entrepreneurs would impede a successful first connection. In a thin market for VC finance, reducing transaction costs by searching through the same channels may increase the likelihood of a successful match (Nightingale et al., 2009). This choice is characterised by strategic complementarity: the optimal

\footnotetext{
${ }^{2}$ We thank an anonymous reviewer for introducing us to this theory.
}

search strategy for the entrepreneur depends on that of the investor and vice versa.

\subsubsection{Evaluation and matching: the investment pitch and due diligence phase}

Investment pitch and due diligence represent the core phases of the actual matching process. The purpose of the pitching and due diligence process is to align and verify perceptions. If investors and entrepreneurs value the venture differently, this impacts the matching probability (Eckhardt et al., 2006). Financial criteria (present financial situation) and return expectations (future financial situation) influence both the decision to take in external capital by entrepreneurs (Söderblom, 2012) as well as the evaluation of the venture by investors (Eckhardt et al., 2006; Petty and Gruber, 2011). Conflicting views in that respect likely lead to a rejection/discontinuation of the cooperation (Higashide and Birley, 2002). But even if entrepreneurs and investors are aligned in this respect, there are still numerous dimensions that matter.

Following earlier work, we can first distinguish between upside potential and downside risk. The literature suggests that cautious investors put more emphasis on downside risk, whereas optimistic entrepreneurs place more weight on the upside potential of the venture (Fried and Hisrich, 1994; Riding and Short, 1987; Shepherd and Zacharakis, 2001). Even if both parties agree on the expected return, this fundamentally different mind-set can lead to a mismatch. We will therefore investigate if and how investors and entrepreneurs differ in this respect.

Second, perceptions about the characteristics of the venture, such as the business model, the technology, its innovativeness and market potential, as well as, e.g., scalability will need to be aligned in order to successfully start a cooperation (Bengtsson and Hsu, 2015; Hsu, 2006; Petty and Gruber, 2011). On the one hand, these aspects are used to signal quality to the investor once the entrepreneur decides to enter the VC market (Bertoni et al., 2015b; Eckhardt et al., 2006; Söderblom, 2012). On the other hand, these characteristics play a significant role in investor decision making in the second stage of the matching process, i.e. the screening, selection and monitoring of investments (Bertoni et al., 2015b; Boocock and Woods, 1997; Fried and Hisrich, 1994; Sørensen, 2007).

A third set of matching criteria include the entrepreneurs' traits and competencies, such as the managerial and technical skills of the entrepreneurial team. These characteristics are obviously used to signal ability to potential investors (Barney et al., 1996; Busenitz et al., 2005; Chen et al., 2009; Hsu, 2007). Petty and Gruber (2011), however, found that the management team is not a decisive factor for investors and that matching might actually work the other way, i.e., entrepreneurs often welcome managerial experience and consultancy services from investors (Bertoni et al., 2015b; Casamatta, 2003). It is then important for investors to understand how the entrepreneur rates specific services that investors may bring to the venture (Barney et al., 1996; Busenitz et al., 2005) and we elicit information on perceived competencies of the founding and investment teams.

Fourth, the matching between entrepreneurs and investors seems to occur based on personal characteristics (Busenitz et al., 2005; Franke et al., 2006; Higashide and Birley, 2002). More specifically, Murnieks et al. (2011) suggest venture capitalists evaluate opportunities represented by entrepreneurs who 'think' in ways similar to their own more favourably, whereas Bengtsson and Hsu (2015) find that sharing characteristics such as the same ethnicity increases the likelihood of a $\mathrm{VC}$ investment and the involvement of the VC in the board of the company. This strongly suggests that a match is easiest when the two sides of the deal 'speak the same language' and understand each other. This enhances trust and reduces transaction costs.

Finally, perceptions of the timing decision should be aligned (Bengtsson and Hsu, 2015). The balance between the prospects for long-term cooperation and the potential for a quick exit should be more or less aligned between the partners as these translate into 
fundamentally different growth strategies and management styles (Hellmann and Puri, 2000; Hsu, 2006).

\subsubsection{Evaluation and matching: risk perception and management}

The behaviour of venture capitalists and entrepreneurs is obviously also influenced by the risk and uncertainty they perceive (Amit et al., 1990; Riding, 2008). Investment in innovation is impaired by information asymmetries between investors and entrepreneurs. Entrepreneurs have an incentive to distort the truth so they have difficulties in credibly conveying both the expected potential and risks of their innovations and corresponding business model (Shepherd and Zacharakis, 2001; Söderblom, 2012). The pitch and due diligence process described above can take care of information asymmetries in the business model and expected returns, but aligning risk perceptions is inherently more complicated. And in handling deep uncertainty, both the investor and the entrepreneur simply have to take a position.

Wüstenhagen and Teppo (2006) and others (Criscuolo and Menon, 2015; Mazzucato and Semieniuk, 2017; Mrkajic et al., 2016) identify market risk, technology risk, policy risk and finance risk associated with new ventures. Market risk refers to the possibility that the product will not be sold in sufficient quantities due to competitors or barriers to entry. This is usually well understood by venture capital investors but may be under- or overestimated by entrepreneurs, leading to a misaligned valuation of the venture. Technology-risk entails the risk that the technology will fail, or only function with significant delays and/or higher costs. These risks are typically well understood by the entrepreneur whereas most VC investors are reluctant to take these on (Criscuolo and Menon, 2015). Policy-risk refers to changing government regulation that affects the venture's business model and thus can deter VC funding decisions (Kenney and Hargadon, 2012; Polzin et al., 2017; Wüstenhagen and Teppo, 2006). Finance-risk touches on issues of securing finance and sustaining liquidity (Mrkajic et al., 2016). All four types of risk are important to the valuation of the venture and consequently, diverging points of view on their importance and how to manage them, may cause problems in finding a match.

However, they also largely depend on the sector the venture is operating in. For example more complex industries such as life-sciences, pharma and green tech are generally considered more risky than assetlight industries such as ICT and software development (Bürer and Wüstenhagen, 2009; Lüthi and Prässler, 2011; Lüthi and Wüstenhagen, 2012). We argue here that a common and shared understanding and appreciation of these risks facilitates a deal, especially since the financial crisis has made early-stage investors more risk averse (Block and Sandner, 2009; Cowling et al., 2016). However, it is not a priori clear how diverging risk perceptions would affect the matching process. On the one hand, making a match is potentially impaired by diverging perceptions of these risks as both parties need to agree on appropriate risk management strategies. On the other, one might argue that different risk perceptions are the fundamental reason to trade these risks. That is, if entrepreneurs have a more precise estimate of the technical and investors a more precise estimate of the market risk, this will create a profitable opportunity for them to join forces and share both risks. This is different for policy risk, which is typically perceived by both to be highly detrimental. Given the data limitations we face, we will not resolve this essentially empirical matter. Our data will allow us to investigate if different perceptions on risks exist.

In addition to taking on uncertainty and risk, investors and entrepreneurs may deploy a range of risk management techniques (Parhankangas and Hellström, 2007). Depending on the perception of the importance of these techniques, VCs and entrepreneurs are more or less likely to cooperate (Chassot et al., 2014; Wüstenhagen and Teppo, 2006). First, a thorough legal and financial due diligence as well as external expert advice are usually called upon by the investor to reduce information asymmetry and gain insight into technical, legal and financial aspects of the venture. Entrepreneurs may want to be cautious not to disclose proprietary information (Parhankangas and Hellström, 2007). Second, and related, the investor usually stresses the importance of formal intellectual property rights (Harhoff, 2011) to mitigate technological and market risk/uncertainty, whereas entrepreneurs may find this a long, costly and cumbersome process. Third, the importance of initial customers and a marketing strategy, valued by a VC, is usually underestimated by entrepreneurs (Baum and Silverman, 2004; Hellmann and Puri, 2002). Different emphasis on these initial marketing activities could lead to a mismatch (Hsu, 2006). Finally, investors typically stage the investment to limit the commitment in the early stages and contract on milestones and KPIs for the venture to fulfil to unlock further investment (Bengtsson and Hsu, 2015). If the staging of the investment is not made clear and attractive to the entrepreneur this could lead to a fundamentally different perception of the relationship and thus end in rejection or early exit (Eckhardt et al., 2006). In short, a divergent perception of the appropriate risk management strategies to be employed is important to establish as well and we have included questions in our study to cover this aspect in the matching process.

\subsection{Signalling and matching challenges are exacerbated in the green tech sector}

For both practical and theoretical reasons, we have limited our data collection effort focussing mainly on investors and entrepreneurs in the green tech sector (see also Migendt et al., 2017). Green technologies are associated with benefits such as reduced costs of materials, capital and labour as well as reduced risks (Ambec and Lanoie, 2008). Green tech investments are also associated with higher managerial and technical complexity (Bocken, 2015; Criscuolo and Menon, 2015; Ghosh and Nanda, 2010; Mazzucato and Semieniuk, 2017) and these nascent markets are characterised by a number of barriers that have financial consequences (Mrkajic et al., 2016; Petkova et al., 2014). High upfront investment (compared to asset-light industries such as ICT), long payback periods, and slow diffusion as a result of dependencies on infrastructure developments, innovation cycles in other industries, national and international regulation and information asymmetries lead to a complex environment in which the matching takes place (Demirel and Parris, 2015; Foxon et al., 2008; Migendt et al., 2017; Polzin et al., 2016).

The need for aligned and the risk of misaligned perceptions are more pronounced in green tech venturing as risks and uncertainty are more prevalent (Dimov et al., 2012; Migendt et al., 2017; Petkova et al., 2014). Moreover, as green tech ventures typically fall under and often depend on new regulation (Ghosh and Nanda, 2010; Hockerts and Wüstenhagen, 2010; Migendt et al., 2017; Mrkajic et al., 2016), policy risk is a key potential source of misaligned perceptions in the case of green tech venture finance. If perceptions on both sides of the market are misaligned, this might be a potentially important factor explaining the lower capital expenditure, shorter exit cycles and a focus on later investment stages that characterises the nascent green tech VC sector (Bocken, 2015; Kenney and Hargadon, 2014, 2012; Marcus et al., 2013).

\section{Methods}

\subsection{Research design}

We have argued above that the matching process is probably easier when perceptions are more aligned going into the process. And we have established that, for misaligned perceptions to frustrate matching, a 
first and necessary condition is to establish that indeed perceptions differ on relevant dimensions. This is only a first step in establishing and testing the full hypothesis empirically. The assumption that matching is easier when perceptions of the other party are aligned can only be tested in full in a sample of matched and non-matched investorentrepreneur pairs. Given that misalignment of perceptions is a necessary condition for our assumption to hold, our method is designed to test for the existence of perception (mis)alignment, not the effect that such perception (mis)alignment has on matching probabilities. Establishing misalignment of perceptions on both sides of the market is less complicated but remains challenging.

In line with previous research, the perspective of both entrepreneurs and investors on the investment process as well as the entrepreneurial team (self vs. third party evaluation) is necessary to understand if (mis) alignments arise (Eckhardt et al., 2006; Riding and Short, 1987; Sørensen, 2007). We expect the misalignment to be greater for those entrepreneurs who have not successfully acquired external business angels or VC funding, as successful entrepreneurs typically have gained first-hand experience with the other side through repeated interaction (Bengtsson and Hsu, 2015; Franke et al., 2006; Ruef et al., 2003). Therefore, to avoid endogenous selection biases, we need information on perceptions from both successful and unsuccessful entrepreneurs and investors. Unfortunately, it is easier to identify and get survey responses from successful entrepreneurs.

In our survey, 30 out of 56 entrepreneurs were successful in attracting investment, whereas investors indicated that only about 1 of 10 proposals move to the next stage and $<2 \%$ of all proposals get funded. These results are also seen in our interviews where it holds for 6 of the 10 entrepreneurs. The sample is therefore not representative of the population. It under-samples non-invested entrepreneurs; but non-invested and invested can be considered representative for their respective categories. Having collected our data from two different institutional contexts (The Netherlands and Sweden) increases the external validity of our results on that dimension. But of course, data from only two countries can never be representative for the universe of institutional contexts in Europe and worldwide. Also, to keep our data collection manageable, we restricted our attention to green tech entrepreneurs and investors in the interviews. We did not, however, prevent or exclude non-green tech investors or entrepreneurs from filling out our survey, which allows us to test for robustness over the industry dimension.

As this is the first systematic study of perception alignment we are aware of, we used both qualitative (i.e., interviews, archival data analysis, participant observation) and quantitative tools (i.e., survey research). This mixed methods approach is also often referred to as 'triangulation', defined as 'the use of two or more methods that draw on different meta-theoretical assumptions (i.e. that are cross-paradigmatic)' to validate conclusions drawn from one method with data obtained through another (Jick, 1979; Moran-Ellis et al., 2006, p. 46). Hence we combine in-depth understanding with assessing magnitude and frequency of constructs (Creswell and Clark, 2010; Haegeman et al., 2013; Olsen, 2004; Tapio et al., 2011). We collected our data from semi-structured interviews and a survey of entrepreneurs and investors. $^{3}$

The combination of both methods allows for the emergence of new constructs and unexpected results (inductive) in the first (qualitative) phase of the research whereas in the later stages by then known assumptions and/or propositions can be verified. The gathered data is then merged, connected and embedded in the research context (Creswell and Clark, 2010). More specifically, the information obtained in the interviews we conducted has informed and inspired the questions

\footnotetext{
${ }^{3}$ An aligned survey consists of a general part, a part for investors and one for entrepreneurs, with questions that are 'aligned' in the sense that we asked entrepreneurs about their perception of investors' opinions on matters we asked the investors about.
}

included in the survey we conducted. In this case we were able to reflect on the perception of the investment process and its context of both entrepreneurs and investors by also using quantitative survey data (Eisenhardt, 1989).

\subsection{Research context and data collection}

Our data collection took place in the context of an international research project looking at the differences of early stage green tech investing in their policy environment to stimulate private investments in the Netherlands and Sweden between 2013 and 2015 (Adenfelt et al., 2014, 2013; Polzin et al., 2017). The two countries are similar in the sense that they are both small, open countries relying heavily on international trade with a large and advanced knowledge base and a highly educated labour force. They are both committed to achieving significant $\mathrm{CO}_{2}$ reduction either by a national roadmap or by adhering to the 20-20-20 targets of the European Union (Adenfelt et al., 2013). Both countries therefore spend significant money and effort in promoting early stage green tech investments. However, they differ in their policy approaches with regard to support in early stage investments. The Swedish government relies more on 'soft' instruments such as networking whereas the Dutch administration is focused on subsidising green energy production (Adenfelt et al., 2013; Polzin et al., 2017). This difference in policy approach was not investigated further in this paper. Moreover, Sweden would qualify as a Nordic country, whereas The Netherlands is typically classified as continental when we follow the varieties of capitalism literature (Hall, 2015; Hall and Soskice, 2001).

Both The Netherlands and Sweden, particularly when compared to Anglo-Saxon equity markets, can be characterised as 'thin markets' for entrepreneurial finance (Bertoni et al., 2015a; Lerner and Tåg, 2013; Li and Zahra, 2012; Nightingale et al., 2009). This certainly holds for early-stage green tech finance which includes only a few active players and deals (McCrone et al., 2016). Fig. 1 shows the cumulated amounts of VC and private equity (PE) invested in green tech companies normalised by average GDP 2007-2014.

We conclude from these numbers that even in the UK the green tech VC sector is quite small and this is a fortiori the case in the smaller markets in The Netherlands and Sweden. By focusing our attention in the interviews on the green tech sector (but allowing in the survey for entrepreneurs and investors active in others sectors to also contribute their data), we hope to cover a significant share of at least this section of the VC market. As we expect asymmetric information problems to be strongest in this high capital and knowledge intensive sector where policy risk is prevalent (Criscuolo and Menon, 2015), we thus investigate a segment of the market in which we are most likely to find our necessary condition fulfilled.

\subsubsection{The interview study}

We first conducted qualitative interviews to make a comparative study of the investment decision processes in the green tech sector in both The Netherlands and Sweden (Adenfelt et al., 2014, 2013). Open interviews are an appropriate method for explorative questions (Moran-Ellis et al., 2006; Yin, 2009). Through Dutch and Swedish VC industry associations as well as the researchers' personal networks, we identified suitable, typical cases (see also Bürer and Wüstenhagen, 2009; Polzin et al., 2016). Our selection criteria for the interviewees included early stage investors ${ }^{4}$ and early stage entrepreneurs ${ }^{5}$ that have recently (the last six months before the interview) been involved in an investment decision (positive or negative). 6 out of 10 interviewed entrepreneurs acquired external finance.

\footnotetext{
${ }^{4}$ VC, financial institutions when relevant with 5-20 years industry experience and corresponding investment portfolio in the two countries and/or Europe, middle aged, both men and women.

${ }^{5}$ Founders or senior employees at small- and medium-sized firms in their early stages, defined by the Global Entrepreneurship Monitor (GEM) as up to three and a half years old, and in different spheres of green tech.
} 


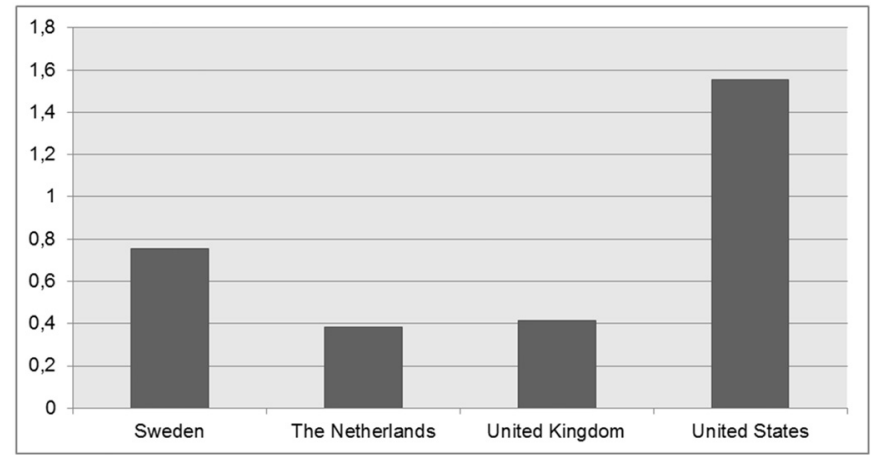

Fig. 1. Green tech VC/PE investments in SWE, NL, UK and US, in the period 2007-2014 (USDk) normalised by average GDP 2007-2014 (USDm) (InvestEurope, 2016; NVCA, 2016; OECD, 2017)

We follow the two major VC/PE industry associations (InvestEurope, 2016; NVCA, 2016) and we use as a proxy for green tech sectors: Alternative energy, Environmental services, Business and industrial products, Biotechnology, Energy: Other, Other cleantech. (For interpretation of the references to colour in this figure legend, the reader is referred to the web version of this article.)
Our semi-structured interview guide ${ }^{6}$ consists of four parts. First, we asked about the general characteristics of the firm or investment fund and the role of the interviewee in that organisation. The second set of questions referred to the funding process. For entrepreneurs, this related to their firm and for investors their typical firm investment process. We then asked questions about the funding of early stage firms and early stage investment, zooming in on the decision-making process. Finally, we asked questions about how entrepreneurs found the right investor and questions about the importance of their network.

Interviews were conducted face-to-face or via telephone and lasted on average one hour (between $40 \mathrm{~min}$ and $2 \mathrm{~h}$ ). These were recorded and transcribed verbatim (Patton, 2002). 2 interviewers in The Netherlands and 3 in Sweden, often in pairs, performed a total of 30 interviews. We classified the interviews into four different groups to detect differences within and between each group and to examine the phenomena studied from different perspectives (Patton, 2002; Yin, 2009). The different types of interviewees are: entrepreneurs in an incubator or not and business angels and venture capital investors in private or public venture capital.

Table 1

Overview about of the interview study (Types of actors, country descriptive statistics).

\begin{tabular}{|c|c|c|c|c|c|}
\hline Code & Type of actor & Country & Type & Date & \# interviewers \\
\hline SE1 & Entrepreneur - Not Incubator & Sweden & Face to face & Oct 2014 & 2 \\
\hline SE2 & Entrepreneur - Incubator & Sweden & Face to face & Oct 2014 & 1 \\
\hline SE3 & Investor - Business angel & Sweden & Face to face & Oct 2014 & 1 \\
\hline SE4 & Investor - Business angel & Sweden & Face to face & Oct 2014 & 2 \\
\hline SE5 & Investor - Public VC & Sweden & Face to face & Oct 2014 & 2 \\
\hline SE6 & Investor - Public VC & Sweden & Phone & Oct 2014 & 1 \\
\hline SE7 & Investor - Business Angel & Sweden & Face to face & Oct 2014 & 2 \\
\hline SE8 & Investor - Public VC & Sweden & Face to face & Oct 2014 & 1 \\
\hline SE9 & Investor - Private VC & Sweden & Face to face & Oct 2014 & 2 \\
\hline SE10 & Investor - Private VC & Sweden & Face to face & Oct 2014 & 2 \\
\hline SE11 & Entrepreneur -Incubator & Sweden & Face to face & Oct 2014 & 2 \\
\hline SE12 & Investor - Business angel & Sweden & Phone & Oct 2014 & 1 \\
\hline SE13 & Investor - Private VC & Sweden & Face to face & Nov 2014 & 1 \\
\hline SE14 & Entrepreneur -Incubator & Sweden & Face to face & Nov 2014 & 2 \\
\hline SE15 & Investor - Private VC & Sweden & Face to face & Nov 2014 & 1 \\
\hline SE16 & Investor - Private VC & Sweden & Face to face & Nov 2014 & 2 \\
\hline NL1 & Investor - Public VC & Netherlands & Face to face & Oct 2014 & 1 \\
\hline NL3 & Investor - Private VC & Netherlands & Phone & Nov 2014 & 1 \\
\hline NL4 & Investor - Private VC & Netherlands & Face to face & Oct 2014 & 1 \\
\hline NL5 & Investor - Private VC & Netherlands & Face to face & Nov 2014 & 1 \\
\hline NL6 & Investor - Private VC & Netherlands & Phone & Nov 2014 & 1 \\
\hline NL7 & Investor - Private VC & Netherlands & Face to face & Oct 2014 & 1 \\
\hline NL8 & Investor - Public VC & Netherlands & Face to face & Nov 2014 & 1 \\
\hline NL11 & Entrepreneur - Not Incubator & Netherlands & Face to face & Sep 2014 & 1 \\
\hline NL13 & Investor - Business Angel & Netherlands & Phone & Sep 2014 & 1 \\
\hline NL15 & Entrepreneur - Incubator & Netherlands & Face to face & Oct 2014 & 2 \\
\hline NL16 & Entrepreneur - Not Incubator & Netherlands & Face to face & Nov 2014 & 1 \\
\hline NL17 & Entrepreneur - Incubator & Netherlands & Face to face & Sep 2014 & 1 \\
\hline NL18 & Entrepreneur - Not Incubator & Netherlands & Face to face & Sep 2014 & 1 \\
\hline NL19 & Entrepreneur - Incubator & Netherlands & Face to face & Sep 2014 & 1 \\
\hline
\end{tabular}

The 'sample' of 30 interviews we could conduct is obviously by no means representative for the entire venture capital sector (see Table 1). It oversamples successful entrepreneurs and exclusively has green tech investors and entrepreneurs by intent. But we did manage to interview representatives of several of the larger funds active in the green tech sector in both The Netherlands and Sweden. In that sense, the interview study covers that sector quite adequately. The interviewed cases can thus be regarded as typical, although not representative for the general population of investors and entrepreneurs in the Dutch and Swedish green tech sector (Seawright and Gerring, 2008). The unique contribution of this paper is that we explored both sides of the investment process with similar semi-structured interviews to obtain comparable data.

\subsubsection{Survey study}

Based on the theoretical framework (Section 2) and the qualitative study, we also developed a survey instrument to verify and extend our

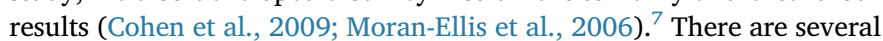
important aspects to be considered when using this methodological approach. First, we should consider the difference between respondents and non-respondents (response bias). As we followed a typical case approach, we expect our respondents not to be significantly different

\footnotetext{
${ }^{6}$ The interview guide can be obtained from the authors upon request.

7 The questionnaire can be obtained from the authors upon request and is still active online at: http://www.matchinvent.nl/survey/index.php/155426.
} 
Table 2

Descriptive statistics of responses to the survey items.

\begin{tabular}{|c|c|c|c|c|c|c|}
\hline Matching variable & Obs. & Mean & Std. Dev & Min & Max & Variable description \\
\hline \multicolumn{7}{|l|}{ Networks to generate deal flow (How important do you rate the following items?) } \\
\hline Fairs and conferences & 64 & 5.16 & 3.32 & 1 & 10 & 10-point Likert scale \\
\hline TV, press and magazines & 63 & 4.03 & 3.03 & 1 & 10 & 10-point Likert scale \\
\hline Friends and family & 66 & 5.94 & 3.46 & 1 & 10 & 10-point Likert scale \\
\hline Actively going after them & 65 & 8.49 & 3.01 & 1 & 10 & 10-point Likert scale \\
\hline Business relations & 66 & 8.61 & 2.71 & 1 & 10 & 10-point Likert scale \\
\hline Incubators & 65 & 5.88 & 3.13 & 1 & 10 & 10-point Likert scale \\
\hline \multicolumn{7}{|l|}{ Pitch and due diligence (How important do you (the investors) rate the following items?) - except for 'credible exit' } \\
\hline The financials & 55 & 5.76 & 2.50 & 1 & 10 & 10-point Likert scale \\
\hline The business model (scalability) & 54 & 8.59 & 1.67 & 4 & 10 & 10-point Likert scale \\
\hline The technology & 54 & 6.81 & 2.14 & 1 & 10 & 10-point Likert scale \\
\hline The innovativeness & 54 & 6.91 & 2.15 & 2 & 10 & 10-point Likert scale \\
\hline The market potential (internationally) & 54 & 8.78 & 1.56 & 3 & 10 & 10-point Likert scale \\
\hline The managerial skills of the entrepreneurial team & 55 & 7.89 & 2.13 & 1 & 10 & 10-point Likert scale \\
\hline The technical skills of the entrepreneurial team & 54 & 6.89 & 2.13 & 1 & 10 & 10-point Likert scale \\
\hline Potential of long-term cooperation & 52 & 6.25 & 2.42 & 1 & 10 & 10-point Likert scale \\
\hline Promised/Credible exit (in years) & 54 & 4.99 & 2.29 & 1.33 & 10 & Numeric value: years \\
\hline Potential for a quick exit & 54 & 5.06 & 2.78 & 1 & 10 & 10-point Likert scale \\
\hline $\begin{array}{l}\text { High upside potential vs. a low downside risk (1 leaning totally towards high-upside potential and } 10 \text { leaning towards } \\
\text { downside risk) }\end{array}$ & 49 & 3.41 & 2.41 & 1 & 10 & 10-point Likert scale \\
\hline \multicolumn{7}{|l|}{ Risk attitudes (How important do you rate the following items?) - except for 'risk self-assessment' } \\
\hline Risk self-assessment (Caliendo et al., 2009) & 52 & 7.87 & 2.28 & 1 & 10 & 10-point Likert scale \\
\hline Technical risk in ICT: The risk that the technology will not work or cannot be scaled & 30 & 4.63 & 3.15 & 0 & 10 & 10-point Likert scale \\
\hline Technical risk in life sciences & 18 & 4.83 & 4.26 & 0 & 10 & 10-point Likert scale \\
\hline Technical risk in renewable energy & 21 & 3.67 & 3.55 & 0 & 10 & 10-point Likert scale \\
\hline Market risk in ICT: the risk that the product/service finds no profitable market & 19 & 4.05 & 3.54 & 0 & 10 & 10-point Likert scale \\
\hline Market risk in life sciences & 20 & 4.30 & 3.31 & 0 & 10 & 10-point Likert scale \\
\hline Market risk in renewable energy & 30 & 5.70 & 3.15 & 0 & 10 & 10-point Likert scale \\
\hline Policy risk in ICT: government policies make the venture impossible or unprofitable & 21 & 3.76 & 3.04 & 0 & 10 & 10-point Likert scale \\
\hline Policy risk in life sciences & 30 & 3.17 & 2.63 & 0 & 10 & 10-point Likert scale \\
\hline Policy risk in renewable energy & 18 & 3.50 & 3.75 & 0 & 10 & 10-point Likert scale \\
\hline Finance risk in ICT: the risk that the venture will fail due to lack of funding & 30 & 6.37 & 3.15 & 0 & 10 & 10-point Likert scale \\
\hline Finance risk in life sciences & 18 & 3.50 & 3.88 & 0 & 10 & 10-point Likert scale \\
\hline Finance risk in renewable energy & 21 & 5.52 & 3.76 & 0 & 10 & 10-point Likert scale \\
\hline \multicolumn{7}{|l|}{ Risk management (How important do you rate the following items?) } \\
\hline Thorough legal and financial due diligence & 49 & 5.90 & 2.44 & 1 & 10 & 10-point Likert scale \\
\hline Get expert advice on technology & 49 & 6.61 & 2.27 & 1 & 10 & 10-point Likert scale \\
\hline Protect intellectual property & 49 & 6.35 & 2.33 & 1 & 10 & 10-point Likert scale \\
\hline Launching customers and order book & 48 & 7.60 & 2.08 & 2 & 10 & 10-point Likert scale \\
\hline Stage finance in rounds & 49 & 6.33 & 2.46 & 1 & 10 & 10-point Likert scale \\
\hline Set milestones and KPIs & 48 & 6.75 & 2.60 & 1 & 10 & 10-point Likert scale \\
\hline
\end{tabular}

from the industry average. Second, common method bias (i.e., gathering all information for this analysis via a survey) could be present. This type of bias generally affects survey data (Podsakoff et al., 2003). We reduced the bias by minimising item ambiguity in the questionnaire. This included avoiding vague concepts, complicated syntax and unfamiliar terms. We deliberately kept questions simple, specific and concise. We also guaranteed respondents' anonymity.

In the period from April 2015-January 2016, Swedish and Dutch entrepreneurs and investors were surveyed using a fully structured online survey (82 questions in 39 groups). The descriptive statistics are reported in Table 2. The questionnaire consisted of items relating to the perception of the investment process by entrepreneurs and investors, notably channels to generate deal flow, pitching and due diligence, risk perception and the importance of characteristics of the entrepreneurial/ investment team. We gathered key performance indicators and the level of agreement with statements was determined. We used 5-point and 10point Likert scales as well as open and closed questions. In total 819 investors or entrepreneurs received an invitation to participate in the survey and we advertised the survey in several entrepreneurial and private equity investor networking events. ${ }^{8}$ In contrast to the interview study, the pool of invited survey participants was not restricted to green

\footnotetext{
${ }^{8}$ It should be noted here that, by advertising the survey at such events, we may have attracted non-Dutch and non-Swedish investors and entrepreneurs to the survey. Also, the survey thus covers non-green tech investors and entrepreneurs.
}

tech. We applied the same survey to all participants, but asked the respondents in some questions to reflect on Green Tech (and ICT and Life Sciences) specifically. ${ }^{9}$

We collected 46 complete and 36 incomplete surveys, which represents a response rate of $10.1 \%{ }^{10} 56$ entrepreneurs and 18 investors participated. 30 entrepreneurs had investment experience. Although the target group was like the one in the interview study, these two samples are distinct. Our participants were mostly highly educated (postgraduate degree) and had backgrounds in Engineering, Business, Sciences, Medicine and Law (in descending order). These variables, alongside industry experience, correspond to other studies in the field of early stage green tech finance (Bürer and Wüstenhagen, 2009; Chassot et al., 2014).

\subsection{Data analysis}

First, the interviews were read and relevant information was extracted. In order to avoid interpretation bias, each interview was read

\footnotetext{
${ }^{9}$ We did so when we asked about arguably highly sector specific aspects, for example, the importance of market, political and technical risk.

${ }^{10}$ It is hard to compute a precise response rate as general advertising of the survey at events reaches many more (but is generally also less effective) than direct personal invitations. The number of observations from these events, however, does not exceed a handful in our sample.
} 
by at least two members of the project team (Patton, 2002). The data was then categorised, coding key terms that are related to our theoretical framework. For the data analysis and data management, the software tool MaxQDA 11.1 was used. The coding scheme that incorporates the theoretical framework is included in the supplementary online material. We present the results across interviews by referring to a view expressed by two or more individuals in a group with the group name e.g., 'some investors ...', if we saw a consensus among all informants in one group, it was labelled 'many entrepreneurs ...'.

Second, we analysed the survey results. The data analysis was conducted in several steps. First, the dataset has been thoroughly screened and cases with missing or absurd values have been excluded (e.g., cases when there was no variance in the answers). This concerned only 8 cases in total. When checking these cases on demographics, their characteristics did not differ markedly from the rest of the sample. Second, we selected central variables for our analysis based on our theoretical framework. Third, we matched investor and entrepreneur questions to obtain a single sample and to do between group comparisons (i.e., comparing their perception of central constructs). Finally, we conducted simple $t$-test analyses using Stata 13.1 to determine the level of agreement about the questions among entrepreneurs and investors.

Third, the results of qualitative and quantitative analyses have been merged and connected to each other. As the coding scheme and subsequent survey build upon the same conceptual background, the comparison of key constructs relating to the investment process between qualitative and quantitative results (as well as a contextualisation of quantitative results through the interviews) was straight forward. Qualitative statements of both entrepreneurs and investors as well as the results of the $t$-test analysis were combined to determine of the overall level of 'perception alignment' in our sample.

\section{Results and discussion}

In our inquiry we aim to answer the question: Do investors and entrepreneurs perceive critical stages in the matching process differently? The results of the statistical analysis can be found in Tables 3-6. We discuss the results together in the sections below following our conceptual framework in Section 2. First we look at the searching stage and for the matching stage to distinguish between 'pitching and due diligence' and 'risk' as in Eckhardt et al. (2006).

\subsection{Searching: social networks and deal flow}

Our results point towards high mismatch in perceptions about the usefulness and beneficial role of networking through various channels. Investors rate fairs and conferences, classical media and personal relations as more important than entrepreneurs. Entrepreneurs are less likely to target these channels, making a matching less likely to occur. Table 3 shows that both in intensity and rank the entrepreneurs deviate quite significantly from the investors. This is also nicely illustrated in the following two quotes:

There are too many events. I can't keep track of them anymore (NL19 Entrepreneur).

Basically, you read, you look at what is happening in the market, you go to conferences, you talk to high-level individuals who know a lot about these markets and discuss it with them [the entrepreneurs] (NL1 Investor).

Still, at most fairs and conferences there is typically no shortage of eager and enthusiastic entrepreneurs. The fact that our entrepreneurs seem less enthusiastic about such events may be because they are typically already somewhat more experienced and they may have switched to other, more effective channels. Some of the more experienced entrepreneurs (i.e., who already raised funds and who were more advanced in the start-up process) also saw the importance of networking and building relationships proactively to get advice and secure investments in the future. Inexperienced entrepreneurs, by contrast, do not seem to consider networking to be an important activity. That said, entrepreneurs perceive that it is more important to actively go after the investors than vice-versa (i.e., investors actively look for target companies). As one investor put it:

Some investors who have been rather successful in their marketing had to shut down their websites and make themselves unavailable in order to not drown in the deal flow (SE15 - Investor).

Finally, investors and entrepreneurs agree on the usefulness of general business relations and incubators to get in contact. ${ }^{11}$ This holds for both entrepreneurs who have received investment and those who have not. Again, three quotes are illustrative:

We were very active and contacted our own networks to ask for help in finding an interested partner. It was a process that started with close partners and then extended to the outer network (SE1 - Entrepreneur).

We mainly came into contact with them through the incubators. These are programmes where you actively explore the market and talk to potential customers [...] to know whether the business model is viable or not (NL19 - Entrepreneur).

In our network, there are incubators [...] that sometimes tell us: 'this is a really interesting company I came across', or 'you should talk to these guys' (NL7 - Investor).

Table 3

Survey results - means comparison analysis (networks to generate deal flow)

\begin{tabular}{llll}
\hline Matching variable & Obs. & $\begin{array}{l}\text { Mean (std. dev) } \\
\text { investors }\end{array}$ & $\begin{array}{l}\text { Mean (std. dev.) } \\
\text { entrepreneurs }\end{array}$ \\
\hline Fairs and conferences & 64 & $6.90(0.84)^{* *}$ & $4.8(0.46)^{* *}$ \\
TV, press and magazines & 63 & $5.70(1.04)^{* *}$ & $3.72(0.40)^{* *}$ \\
$\begin{array}{l}\text { Friends and family } \\
\text { Actively going after }\end{array}$ & 66 & $7.73(0.90)^{* *}$ & $5.58(0.47)^{* *}$ \\
$\quad 65$ & $6.73(1.24)^{* *}$ & $8.85(0.36)^{* *}$ \\
$\quad \begin{array}{l}\text { them } \\
\text { Business relations }\end{array}$ & 66 & $8.36(1.00)$ & $8.66(0.35)$ \\
Incubators & 65 & $6.40(1.05)$ & $5.78(0.42)$ \\
\hline
\end{tabular}

$*, * *, * * *$ refer to statistically significant differences on the 10,5 and $1 \%$ level respectively. Stata command $t$-test was used.

${ }^{1}$ One might argue that all items listed in this table somehow 'measure' the importance the respondents attach to networking and searching and some suggested doing a factor analysis to check if indeed these items measure the same underlying construct. We have and indeed some clustering does take place. But we present the individual items here (and in tables that follow) to explore in more detail if and where entrepreneurs and investors differ in their answers to the same questions. If we clustered by group, the interpretation of the differences would be less intuitive. Therefore, we decided not to include the cluster analysis results here.

Our results on the searching stage of the matching process in thin markets contribute to the discussion about the importance of social networks for accessing venture capital resources (Berger et al., 2005; Nightingale et al., 2009; Petersen and Rajan, 2002; Stein, 2002). As meeting prospective investors and entrepreneurs is a precondition for matching, we argue that a difference in perception of the importance of

\footnotetext{
${ }^{11}$ Part of the statistically significant difference in means reported in Tables 3-6 could be due to systematic differences between how entrepreneurs and investors rank options and score alternatives on a 10-point Likert scale. We have estimated means for every respondent for each question in 'networks to generate deal flow', 'pitching and due diligence', 'risk perception and risk assessment' and 'risk management' separately. Investors rank the first item set slightly higher than entrepreneurs, but only on a $10 \%$ significance level. Entrepreneurs have a higher mean regarding risk management techniques $(5 \%$ significance level). There are no other significant differences. We also estimated means for all variables and then ran a $t$-test which yielded no significant difference between entrepreneurs and investors.
} 
search channels reduces the likelihood that investors and entrepreneurs will find a suitable match without incurring high search costs. ${ }^{12}$ Let us now assume contact has been established and we proceed with the matching stage.

\subsection{Evaluation and matching: pitching and due diligence}

After meeting, entrepreneurs will typically pitch or present their ideas and investors evaluate and assess the value of the proposition. This part represents the aligned part of the survey. Hence investors were asked to rate the importance of certain aspects of the investments whereas entrepreneurs described how they thought the investors would evaluate these items.

\subsubsection{Risk/return expectations}

In our interviews and survey, both entrepreneurs and investors were asked how investors would rate the importance of 'high upside potential' vis-a-vis 'low downside risk'. Interestingly, the investors themselves rated the upside potential significantly higher than the entrepreneurs think investors would rate it (see Table 4). ${ }^{13}$ This is supported by our interview quotes:

Minimising a loss is non-existent among the investors we work with. It is always the upside you are after (SE4 - Investor). Security is what investors want (SE1 - Entrepreneur)

but:

[Our product] is full of risks and uncertainties. Controlling it is a fairy tale (NL16 - Entrepreneur).

Our findings deviate from the commonly held view that cautious investors put more emphasis on managing and mitigating downside risk whereas optimistic entrepreneurs instead place more weight on the upside potential of the venture (Fried and Hisrich, 1994; Riding and Short, 1987; Shepherd and Zacharakis, 2001). According to our interviews as well as in our survey (see Table 4), entrepreneurs overestimate the risk-mitigation attitude of investors and both groups focus on the upside potential.

\subsubsection{Venture properties}

First, the financials are deemed relevant by investors when they evaluate a company. But investors not only care about promised returns and exit strategies. The financials help build confidence and comfort as well:

The financials of the company [are important]; we must believe the financial plan (NL4 - Investor).

The investor is seriously investing in tech and hardware, they want to see both [numbers and details on technology] (SE14 - Entrepreneur).

However, when looking at the survey results it becomes clear that entrepreneurs underestimate the importance of the financials for investors. This is not necessarily contradictory. In interviews, when asked about the business model and financial criteria, all agree they are important. Investors also stressed in the interviews that they invest in companies with business ideas that they understand. On the one hand, this might mean high tech ventures thus have a harder time obtaining finance as they bring innovative technology to the market. On the other hand, such innovativeness is also highly ranked by investors in the survey. Most importantly, the entrepreneur should therefore be able to explain to an investor how the venture will be technically viable and commercially successful. In the survey, we asked both sides to quantify the importance investors would attach to that criterion. This creates some room for disagreement on the intensity, if not on the general statement of importance.

When asked about the importance of the business model and scalability, both investors and entrepreneurs attach a lot of weight to these issues (see Table 4). Below are some quotes from both groups to illustrate this consensus:

We will never build our own production capacity; we will manage and develop our brands and core-business. Everything else we will buy (SE11 - Entrepreneur).

I would say that one of the important factors for us to invest in a company would be to help globalise the technology or to commercialise it (SE16 - Investor).

Table 4

Survey results - means comparison analysis (pitching and due diligence).

\begin{tabular}{|c|c|c|c|}
\hline Matching variable & Obs. & $\begin{array}{l}\text { Mean importance assigned (std. dev) } \\
\text { investors }\end{array}$ & $\begin{array}{l}\text { Mean importance assigned (std. dev.) } \\
\text { entrepreneurs }\end{array}$ \\
\hline Upside potential more important than downside risk & 56 & $4.20(0.39)^{* *}$ & $3.28(0.19)^{* *}$ \\
\hline The financials & 55 & $4.30(0.84)^{* *}$ & $6.09(0.35)^{* *}$ \\
\hline The business model (scalability) & 54 & $7.89(0.81)^{*}$ & $8.73(0.22)^{*}$ \\
\hline The market potential (internationally) & 54 & $9.22(0.78)$ & $8.69(0.21)$ \\
\hline The technology & 54 & $8.44(0.58)^{* * *}$ & $6.49(0.31)^{* * *}$ \\
\hline The innovativeness & 54 & $9.22(0.43)^{* * *}$ & $6.44(0.30)^{* * *}$ \\
\hline The managerial skills of the entrepreneurial team & 55 & $6.40(1.15)^{* * *}$ & $8.22(0.22)^{* * *}$ \\
\hline The technical skills of the entrepreneurial team & 54 & $6.60(0.87)$ & $6.96(0.30)$ \\
\hline Potential of long-term cooperation & 52 & $6.89(1.23)$ & $6.12(0.32)$ \\
\hline Promised/Credible exit (in years) & 53 & $8.00(0.73)^{* * *}$ & $4.30(0.25)^{* * *}$ \\
\hline Potential for a quick exit & 54 & $2.33(0.37)^{* * *}$ & $5.60(0.40)^{* * *}$ \\
\hline
\end{tabular}

$*, * *, * * *$ refer to statistically significant differences on the 10,5 and $1 \%$ level respectively. Stata command ttest was used.

\footnotetext{
${ }^{12}$ In Sanders and Welters (2013), a similar dynamic for searching in the labour market was modelled and tested. There it was shown that searching (for vacancies and new employees) through different channels reduces the matching efficiency. The same intuition applies here.

13 This, however, should not be over interpreted. We have checked if there are any systematic differences in how investors and entrepreneurs use 5- and 10-point Likert scales to express their opinion and there seems to be no systematic correlation, but a Likert scale remains ordinal. It is therefore hard to interpret a 1 point higher average score beyond concluding that investors seem to lean more towards the potential upside than the entrepreneurs in our sample.
}

It is quite remarkable that the relative rating of investors features innovativeness and technology whereas for entrepreneurs the business model and market potential come out highest in their ranking. Entrepreneurs again underestimate the importance of technology and innovation in the investor's decision-making process. We asked the investors and entrepreneurs to think about the matching process in venture capital and therefore this likely primed them to think of what they would focus on in such a setting. Investors focus on what distinguishes a venture from the many others they see, and then it seems logical that entrepreneurs focus on what they know investors will want to learn 
about.

Our survey specifically highlights the diverging perception of 'hard criteria' in investing in an early stage venture. The general venture capital literature highlights the different business vs. technical mindsets between investors and entrepreneurs with the former focussing on financials and business models (Eckhardt et al., 2006; Petty and Gruber, 2011; Söderblom, 2012). We find that entrepreneurs underestimate the importance investors attach to financials, confirming earlier work (Bengtsson and Hsu, 2015; Hsu, 2006; Petty and Gruber, 2011). We also find, however, that both technology and the degree of innovativeness are rated as more important by the investors themselves than perceived by the entrepreneurs.

\subsubsection{Skills of the entrepreneurial team}

In the interviews, some investors stress that the team is more important than the venture. They suggest that a good team can be successful with a bad idea, but a bad team cannot make a success out of a good idea. They believe they can intervene in the team if necessary. Regarding necessary/successful skills in the entrepreneurial team, investors give a lower priority to the managerial skills than the entrepreneurs would expect them to assign in the survey. This contradicts some of the answers we got in the interviews, e.g.:

Typically, in the US money follows management, right, and that's a luxury you can have if you're in the valley or in Boston. But our fund has been in what we call resource limited areas [Europe], so our investment model is focussed on building the team (NL6 - Investor).

One possible explanation for these diverging answers is presented by one of the investors:

VC firms always talk about the importance of the team... but it is not serious, it is just promotion. The entrepreneur must feel that they are an A-team (SE15 - Investor).

However, both do agree on the importance of the technical skills for the success of the entrepreneurial team. And investors receive great comfort from knowing that especially the technical side is well represented in the founding team.

Obviously, you need the technical mind, whoever that is. [...] And if that's the professor, great (SE16 - Investor).

Managerial skills are expected to be less prevalent among the entrepreneurial team as they are contributed or complemented by the investors (Bertoni et al., 2015b; Busenitz et al., 2005; Petty and Gruber, 2011). Technical skills and a profound understanding of their product and market are highlighted as important by both in about equal measure.

\subsubsection{Entrepreneur-investor relationship}

Investors and entrepreneurs in our survey agree on the fact that the investment should yield the possibility for long-term cooperation. However, when asked about what would constitute a credible exit, the entrepreneurs come up with significantly shorter exit periods. This is supported by our interview results, where the investors perceive investment as entering into a long-term partnership and acknowledge the added value of a good match:

The people have to be the right people. I mean, we look at this as a marriage almost (SE16 - Investor).

Especially less experienced entrepreneurs indicate that they have difficulties finding the right partner.

I think there is enough [money]. What is difficult to find is the right one for you. There are lots of different types of companies at different stages

\section{(NL17 - Entrepreneur).}

The investors in our interviews all realise that an investment is never a one-time event, whereas the entrepreneurs seem less aware of longterm commitment. Entrepreneurs also give 'the potential for a quick exit' a much higher weight in investors evaluating potential investment opportunities than they attribute to this themselves. In our interviews, however, potentially fast exits were not mentioned very often by entrepreneurs, whereas investors do bring this up as part of their business model:

Our fund in general, and our documentation, lasts five years. So, it is rare we'd stay in longer. Usually once the five years are up, they've been purchased by a larger venture or company or maybe they've gone IPO (SE16 - Investor).

This could mean that entrepreneurs are reluctant to take on VC investors as they expect them to look mainly for a quick exit. It would seem, rather, that investors want the entrepreneur to think about the exit, even if it is not a quick one. Alignment of expectations about exit strategies was considered to be important by investors.

You get an idea [...] of how good the entrepreneur is from their exit strategy. Making sure that the team is aligned with the exit is also very important (NL4 - Investor).

Our results on the importance of long-term cooperation potential confirm the notion that a good match between the investors and entrepreneurs is deemed pivotal for success as we know from research it is (Bengtsson and Hsu, 2015; Franke et al., 2006; Higashide and Birley, 2002). These results contribute to the discussion about short-termism in the green tech venture capital industry (Kenney and Hargadon, 2012; Marcus et al., 2013; Mazzucato, 2013). Relatively short cycles ( $<5$ years) are indeed mentioned, but investors seem quite flexible in extending these for the prospective business case. This was supported by the relatively lower importance investors attach to an early exit in our survey and the literature (Hellmann and Puri, 2000; Hsu, 2006). Entrepreneurs, however, seem less aware of this flexibility.

\subsection{Evaluation and matching: risk}

\subsubsection{Risk perception and risk assessment}

Alignment of risk perception differs among the interviewed and surveyed participants (see Table 5). In general, investors assess their willingness to take risks significantly higher than entrepreneurs, which contradicts earlier work that highlights increased risk aversion after financial crises (Block and Sandner, 2009; Cowling et al., 2016).

This heterogeneity is apparent when entrepreneurs and investors evaluate technological, market, policy and finance risks. In our survey we split the sample according to the sector in which they operate to elicit a contextspecific risk perception (Lüthi and Wüstenhagen, 2012). First, entrepreneurs and investors attach more or less the same weight to technological risk as the main barrier for early stage ventures, with this result cutting across ICT, life sciences and renewable energy sectors. In the qualitative interview study, technology, or production risk, seemed more important to investors, whereas the entrepreneurs mentioned this risk less frequently.

Offshore wind - the big challenge there is cost right now. The Dutch government has decided that the levelised cost of offshore wind electricity has to be reduced to $40 €$ per MWh in 10 years' time (NL19 Entrepreneur).

Initially it's the technology risk, during proof of concept or product development, and once your risk starts to decrease, the focus becomes more on the business risk, the market risk, getting the technology into the marketplace (NL6 - Investor). 
Table 5

Survey results - means comparison analysis (risk attitudes).

\begin{tabular}{llll}
\hline Matching variable & Obs. & $\begin{array}{c}\text { Mean (std. dev) } \\
\text { investors }\end{array}$ & $\begin{array}{c}\text { Mean (std. dev.) } \\
\text { entrepreneurs }\end{array}$ \\
\hline Risk self-assessment & 52 & $8.90(0.41)^{*}$ & $7.62(0.37)^{*}$ \\
Technical risk (ICT) & 30 & $5.10(1.04)$ & $4.40(0.70)$ \\
Technical risk (life sciences) & 19 & $5.25(0.92)$ & $3.18(1.20)$ \\
Technical risk (renewable energy) & 21 & $4.60(1.57)$ & $3.50(0.74)$ \\
Market risk (ICT) & 30 & $6.70(0.97)$ & $6.20(0.73)$ \\
Market risk (life sciences) & 18 & $6.71(1.06)^{*}$ & $3.64(1.42)^{*}$ \\
Market risk (renewable energy) & 21 & $6.20(1.59)^{*}$ & $3.67(0.80)^{*}$ \\
Policy risk (ICT) & 30 & $3.70(1.08)$ & $2.90(0.49)$ \\
Policy risk (life sciences) & 18 & $6.43(1.40)^{* * *}$ & $1.64(0.83)^{* * *}$ \\
Policy risk (renewable energy) & 21 & $7.00(1.27)^{* * *}$ & $2.63(0.79)^{* * *}$ \\
Finance risk (ICT) & 30 & $4.70(1.02)$ & $6.20(0.69)$ \\
Finance risk (life sciences) & 18 & $6.14(1.34)^{* * *}$ & $1.82(0.87)^{* * *}$ \\
Finance risk (renewable energy) & 21 & $7.40(1.03)$ & $4.938(1.00)$ \\
\hline
\end{tabular}

ICT: Information and communication technology; LS: Life sciences; RE: Renewable energy; *,**,*** refer to statistically significant differences on the 10,5 and $1 \%$ level respectively. Stata command $t$-test was used.

Entrepreneurs, especially for the life sciences and renewable energy sectors, rate market risk similar in importance to technical risk except for market risk in ICT, which they perceive to be higher. For investors, we see quite a big increase relative to technical risk and consequently they rank the importance of market risk in Life Sciences and Renewable Energy significantly higher than the entrepreneurs. The assessment of market risk in the ICT sector is deemed high by both and does not significantly differ among investors and entrepreneurs.

In the interviews, policy or regulation risk was clearly mentioned and discussed most. It is deemed incalculable and thus perceived as deeply uncertain by both investors and entrepreneurs. In particular investors dislike this type of risk, as it cannot be managed, hedged or avoided. Two Swedish investors phrased this best when they commented:

Capital intensive and long cycles [imply] large uncertainty [...]. 'Will the Swedish policy last?' is a question we asked ourselves (SE3 - Investor).

And:

We generally do not like regulation risk. [...] If you are standing in front of total darkness, we do not invest, no matter how good the upsides are (SE9 - Investor).

That result was supported by the survey study. Policy risk scored highest of all risk categories for the investors. More interesting is that entrepreneurs seem to attach much less weight to it. Our survey data suggest investors perceive policy risks in the life sciences and renewable energy sectors as significantly more important than entrepreneurs. In contrast, this is not the case for ICT. This makes sense as the ICT sector is much less policy driven. Finally, our survey participants also assessed the finance risk. What stands out here is the high (re)financing risk both groups see for renewable energy, while investors are much less worried about this in ICT. Entrepreneurs, on the other hand, seem less worried about financing risks in Life Sciences, where the difference with investors is statistically significant.

In conclusion, our interviews and the literature show that risk assessment plays a central role in the investment process (Criscuolo and Menon, 2015; Mrkajic et al., 2016; Parhankangas and Hellström, 2007; Wüstenhagen and Teppo, 2006). In our survey, we disentangled these risks by type and sector to reflect upon different perceptions and detect mismatches. Policy, market and finance risks are assessed lower by entrepreneurs, except for the VC domain ICT. This result finds support in earlier evidence (Bürer and Wüstenhagen, 2009; Lüthi and Prässler, 2011; Lüthi and Wüstenhagen, 2012). These misaligned perceptions may cause entrepreneurs to value their venture more highly than the investor and would hamper a potential match. Further, we contribute to the discussion on the suitability of VC for green tech investments (Bocken, 2015; Kenney and Hargadon, 2012; Marcus et al., 2013) by highlighting misaligned (policy) risk perceptions as one additional cause for why VC is deemed unsuitable in that sector.

\subsubsection{Risk management}

Once risk perceptions are aligned, investors and entrepreneurs can decide on how to manage them. A range of tools exist to address the risks of early stage investments. Our survey findings (Table 6) suggest that investors and entrepreneurs perceive most risk management techniques as equally important. But there are some differences.

First, entrepreneurs value thorough financial and legal due diligence significantly less than investors. Second, our survey results show general agreement among entrepreneurs and investors on including external advisors to evaluate the technology. This finding extends earlier work (Parhankangas and Hellström, 2007) and makes this an unlikely source of mismatching.

Third, technology is often key to a (green tech) venture and sometimes hard to formally protect. This would imply entrepreneurs may be reluctant to be completely transparent, whereas investors like to see formal protection (IP) (Harhoff, 2011). Entrepreneurs acknowledge this finding and both attach high weights to intellectual property as a risk management tool. The importance of IP is illustrated also in the interviews. An entrepreneur for example stated:

Well 'is there a market and do you have contact with potential customers already?' That's usually the first question. Then, afterwards we state the market we are in and the next question is: 'do you have IP?' (NL19 Entrepreneur).

And from the investor side:

Does it have IP or not, or is it more project organisation - we don't like project organisations, we want to invest in IP (NL7 - Investor).

To address market risk, the two parties also agree that initial customers and an order book showing commercial viability of the venture are very important. This scores the highest among all risk management tools for both groups and supports previous analyses (Baum and Silverman, 2004; Hellmann and Puri, 2002).

The importance of customers (and signalling this to the investors) was also apparent from the interviews:

Table 6

Survey results - means comparison analysis (risk management).

\begin{tabular}{lcll}
\hline Matching variable & Obs. & $\begin{array}{l}\text { Mean (std. } \\
\text { dev) } \\
\text { investors }\end{array}$ & $\begin{array}{c}\text { Mean (std. dev.) } \\
\text { entrepreneurs }\end{array}$ \\
\hline $\begin{array}{l}\text { Thorough legal and financial due } \\
\quad \text { diligence }\end{array}$ & 39 & $6.23(0.35)^{* *}$ & $4.60(0.96) * *$ \\
$\begin{array}{l}\text { Get expert advice on technology } \\
\text { Protect intellectual property }\end{array}$ & 49 & $6.70(0.99)$ & $6.59(0.33)$ \\
$\begin{array}{l}\text { Launching customers and order book } \\
\text { Stage finance in rounds }\end{array}$ & 49 & $6.10(0.95)$ & $6.41(0.35)$ \\
Set milestones and KPIs & 49 & $5.40(1.13) *$ & $7.69(0.35)$ \\
\hline
\end{tabular}

$*, * *, * * *$ refer to statistically significant differences on the 10,5 and $1 \%$ level respectively. Stata command $t$-test was used. 
A company needs to have either a proof of concept or they must have a user, a customer that is utilising that technology in some shape or form (SE16 - Investor).

We are cooperating with pretty large partners and then you perhaps do not want to profile yourself as a start-up (SE2 - Entrepreneur).

Risk can also be managed by staging the investment. Occasionally, investors indicate in the interviews that they will ask prospects to return in a later stage, after some key uncertainties have been resolved. The investors strategically time their commitment by structuring the deal in stages (Bengtsson and Hsu, 2015; Eckhardt et al., 2006). Interestingly, this technique for managing risk is given significantly less weight by investors but this should then not lead to a mismatch in supply/demand of finance. Investors also strategically manage their commitment by involving other investors. This is positively evaluated by investors in our interviews:

In our due diligence of the company, we make sure that there is enough money around the table. But before that we have to have a pretty good idea [on how] to get someone else to invest at a later stage (NL4 Investor).

But entrepreneurs do see some downsides to the strategic management of risks by funds:

However, many of the barriers [relate to the fact] that investors have raised their funds under conditions that they have to [invest in certain industries, in certain stages, in firms with turnover etc.] (SE14 Entrepreneur).

Managing risks by diversification and involving multiple investors increases the need for accountability and measurable performance. This arguably reduces the ability to invest in ventures where a track record is missing and products and markets are yet to be developed. This could also affect the appropriateness of setting milestones and KPIs for the entrepreneurs. In the survey, respondents attached high weight to this, but this finding was not strongly supported by our interview results. Entrepreneurs and investors there did not mention it spontaneously as a way of reducing risks. This could be because in green tech, where our interviewees were active, this way of managing risk is less suitable. Failing to agree on a roadmap and milestones in general may lead to a mismatch between investors and entrepreneurs (Bengtsson and Hsu, 2015; Eckhardt et al., 2006), but it does not seem to be a major barrier to VC investment in the green tech sector.

\subsection{Additional and sensitivity analyses}

In addition to comparing perceptions between investors and entrepreneurs, we split our survey sample by country of origin and green tech vs. non-green tech, pooling investors and entrepreneurs due to limited sample size. We find no significant differences across the countries, in line with our qualitative findings. However, we do find differences regarding green tech vs. non-green tech. On matching, actors in the green tech sector rate the importance of incubators and business relations significantly less than the non-green tech actors. This seemingly contrasts with our qualitative analyses where virtually all actors agreed on the importance of these two channels. In the qualitative interviews, however, it is hard to gauge the intensity and importance interviewees attach to specific channels and mentioning a channel as important is perhaps not the same thing as also rating it high in a list of alternative channels. A possible explanation for this finding would be that green tech specialized incubators are perhaps less prevalent than in Life Sciences and ICT and the density of the business network is also arguably thinner.

Also interesting in our comparison across groups is that green tech actors rate themselves as less risk-taking and they believe a quick exit is a more important criterion. This could impede innovation in this sector
(Kenney and Hargadon, 2014). Finally, the investors we interviewed do not consider green tech different from normal early-stage enterprises. A very telling quote we got in different shapes and forms is that: 'there is no green finance, only finance'. The risk-return they require is no different than the one observed on other ventures in other sectors, as investors evaluate these ventures considering the non-green tech alternatives they also have. In conclusion, there are some, but no significant differences between green and non-green tech ventures when it comes to venture capital investing.

\section{Conclusions and implications}

From this study of entrepreneurs' and investors' perceptions of key stages in the investment process, several conclusions can be drawn. First, to understand why early stage technology investors often fail to provide adequate financing for new high-technology-based firms, we breakdown the matching process into different stages. We find that misaligned perceptions between parties exist in every stage and hypothesise that these misalignments explain why fewer deals than optimal are completed. This diagnosis is different from the more traditional idea that the supply of funds for venture capital investments is lacking. And so is the cure: if matching problems are the bottleneck, 'thickening' markets for venture capital in Europe would then require that we stimulate repeated interaction and communication, such that perceptions become more aligned.

Second, our study has shown that in critical phases of the matching process significant misalignment of perceptions indeed exists. The different perception of channels to meet potential investors/entrepreneurs as well as the overall perception of networking already would lead to a lower number of 'initial contacts' being made. When it comes to pitching, entrepreneurs think that investors rely more on financial and other hard criteria to evaluate the commercial viability of the venture than investors themselves indicate they do. This may cause entrepreneurs to pitch and signal the wrong things. Furthermore, the perceived importance of market, policy and finance risk is misaligned. And entrepreneurs seem to not understand the tools investors have at hand to mitigate these risks. Specifically, investors view the investment decision as a staged, multi-round process, whereas entrepreneurs have a more static view on investments and perceive an investment as a onetime event. Overall, investors seem to accept the challenge of financing potentially disruptive innovation; in fact, that is what they are in the business for. But investors need to reach a certain level of comfort and be allowed to apply their full range of instruments and techniques to assess, evaluate and manage the many risks involved.

Our findings do not uncover any supply constraint or demand problem in European VC markets in general or for green tech in particular. There seem to be sufficient funds to finance any project deemed worthy and there is no shortage of projects looking for funding. Based on our analysis we conclude that misaligned perceptions exist and could create a bottleneck in thin markets for venture capital. This diagnosis requires a different treatment.

\subsection{Implications}

Entrepreneurs are advised to invest in networking activities, especially fairs and conferences to extend their business relations as these are perceived as highly important by investors. In addition, incubators provide a good platform for finding a match. To increase their chances of making a match they should also work on better communicating the policy, market and finance risks associated with their venture. Hence, entrepreneurs should focus on the business case and the technology whilst also developing communication skills to convey the necessary information to investors. In addition an understanding of the personal level of interaction will increase the chance of funding (see also Bengtsson and Hsu, 2015).

Investors are well advised to actively search for potential 
entrepreneurs and expand their network, as the entrepreneurs rely less on channels such as personal networks and business relations. Beyond decision criteria such as technical skills and personal characteristics, investors should disclose their way of risk assessment and risk management to entrepreneurs to enable them to provide the right kind of information and improve the matching probability throughout the pitching and due diligence process.

Policy makers (see OECD, 2015) need to understand this largely social process of matching between investors and entrepreneurs in order to effectively mobilise private finance for innovation (Bocken, 2015; Foxon et al., 2008; Iyer et al., 2015; van den Bergh, 2013). This seems particularly acute for green tech venturing, as the urgent transition to a more sustainable economy involves disruptive technology that cannot come from incumbents. The lack of VC finance for many of the green tech ventures out there may not be an inadequate flow of funds, especially in the 'valley of death' (Kenney and Hargadon, 2012; Marcus et al., 2013), but rather a frustrated searching and matching processes due to a 'thin market'. This implies a very different policy approach.

In line with earlier work (Bertoni et al., 2015b), our findings imply that 'soft instruments' such as start-up competitions and contests, pitching events, training as well as other intermediation activities between investors and entrepreneurs could reduce misaligned perceptions, create a mutual understanding between entrepreneurs and investors. Policy makers could support economic and financial literacy among would-be entrepreneurs as well as provide technical expertise to investors. In the broader discussion, these measures could also 'thicken' the markets for entrepreneurial finance by increasing the (successful) interaction between these two groups. Policy makers cannot be matchmakers, but they can certainly increase the probability of successful matching by organising more intensive interactions.

\subsection{Limitations and future research}

Although the combination of qualitative and quantitative methods addresses some concerns about the generalizability of our findings, our relatively small sample warrants some caution. Our initial simple statistical analyses give indication for misaligned perceptions. We believe this generalizes to the wider population, because our interviews and survey oversampled entrepreneurs that were already successful in finding funding. If anything, one would expect this oversampling to bias the results towards more aligned perceptions. In the survey study, about half the entrepreneur population gained investment experience. If we find misaligned perceptions in this sample, it is likely to be worse in the general population. The small sample size does not allow for more sophisticated econometrics and statistics. Future research could aim to increase our sample of investors and entrepreneurs, such that more sophisticated statistical analysis is possible. Our data also does not allow us to identify the two parties to a proposed match. In other words, this is not a matched pairs study. This implies we cannot verify that, all else equal, misaligned perceptions ex ante indeed reduce the probability of a match being made. Collecting such a dataset while preventing the oversampling of successful matches, however, proves a daunting task. In future, we aim to collect such data at events that bring investors and entrepreneurs together and/or conduct experimental field and lab research with nested matching decisions.

\section{Acknowledgements}

The authors are grateful for the time and support of interviewees and the survey participants. Comments by two anonymous journal reviewers helped tremendously in refining the argument of the paper. The research team would like to thank Frauke Diedrichs, Nnamani Ogechi, Kristin Burrescia, and Lisa Höglind for research assistance and participants in the ELF workshop Mobilising Private Funds for the Transition to a Sustainable Economy in Utrecht, November 2013, the Swedish
Network for European Studies in Economics and Business (SNEE) in Mölle, May 2014 and May 2015, the Ratio workshop in Stockholm in February 2016, and the KTH Royal Institute of Technology workshop in Stockholm in April 2017 for useful comments. This research is part of the Mistra Financial Systems programme (MFS). We also gratefully acknowledge financial support from the European Liberal Forum (grant name 'Green Funding' [616501]) and The Swedish Agency for Youth and Civil Society.

\section{Appendix A. Supplementary data}

Supplementary data to this article can be found online at http://dx. doi.org/10.1016/j.techfore.2017.07.016.

\section{References}

Adenfelt, M., Sanders, M., Stavlöt, U., 2013. Mobilising Private Funds for the Transition to a Sustainable Economy. European Liberal Forum, Brussels.

Adenfelt, M., Sanders, M., Stavlöt, U., 2014. Digging for Gold in the Green Economy: Private Investment in Green Venturing. European Liberal Forum, Brussels.

Ambec, S., Lanoie, P., 2008. Does it pay to be green? A systematic overview. Acad. Manag. Perspect. 22, 45-62.

Amit, R., Glosten, L., Muller, E., 1990. Entrepreneurial ability, venture investments, and Risk sharing. Manag. Sci. 36, 1232-1245.

Audretsch, D.B., Bönte, W., Mahagaonkar, P., 2012. Financial signaling by innovative nascent ventures: the relevance of patents and prototypes. Res. Policy 41, 1407-1421. http://dx.doi.org/10.1016/j.respol.2012.02.003.

Barney, J.B., Busenitz, L.W., Fiet, J.O., Moesel, D.D., 1996. New venture teams' assessment of learning assistance from venture capital firms. J. Bus. Ventur. 11, 257-272. http://dx.doi.org/10.1016/0883-9026(95)00011-9.

Baum, J.A.C., Silverman, B.S., 2004. Picking winners or building them? Alliance, intellectual, and human capital as selection criteria in venture financing and performance of biotechnology startups. J. Bus. Ventur. 19, 411-436.

Bengtsson, O., Hsu, D.H., 2015. Ethnic matching in the U.S. venture capital market. J. Bus. Ventur. 30, 338-354. http://dx.doi.org/10.1016/j.jbusvent.2014.09.001.

Berger, A.N., Udell, G.F., 2003. Small business and debt finance. In: Acs, Z.J., Audretsch, D.B. (Eds.), Handbook of Entrepreneurship Research. Springer-Verlag, New York, pp. 299-328.

Berger, A.N., Udell, G.F., 2006. A more complete conceptual framework for SME finance. J. Bank. Financ. 30, 2945-2966. http://dx.doi.org/10.1016/j.jbankfin.2006.05.008.

Berger, A.N., Miller, N.H., Petersen, M.A., Rajan, R.G., Stein, J.C., 2005. Does function follow organizational form? Evidence from the lending practices of large and small banks. J. Financ. Econ. 76, 237-269. http://dx.doi.org/10.1016/j.jfineco.2004.06. 003.

Bertoni, F., Colombo, M.G., Grilli, L., 2011. Venture capital financing and the growth of high-tech start-ups: disentangling treatment from selection effects. Res. Policy 40, 1028-1043. http://dx.doi.org/10.1016/j.respol.2011.03.008.

Bertoni, F., Colombo, M.G., Quas, A., 2015a. The patterns of venture capital investment in Europe. Small Bus. Econ. 45, 543-560. http://dx.doi.org/10.1007/s11187-0159662-0.

Bertoni, F., D'Adda, D., Grilli, L., 2015b. Cherry-picking or frog-kissing? A theoretical analysis of how investors select entrepreneurial ventures in thin venture capital markets. Small Bus. Econ. 46, 391-405. http://dx.doi.org/10.1007/s11187-0159690-9.

Block, J., Sandner, P., 2009. What is the effect of the financial crisis on venture capital financing? Empirical evidence from US Internet start-ups. Venture Cap. Int. J. Entrep. Financ. 11, 295-309. http://dx.doi.org/10.1080/13691060903184803.

Bocken, N.M.P., 2015. Sustainable venture capital - catalyst for sustainable start-up success? J. Clean. Prod. 108, 647-658. http://dx.doi.org/10.1016/j.jclepro.2015.05. 079.

Boocock, G., Woods, M., 1997. The evaluation criteria used by venture capitalists: evidence from a UK venture fund. Int. Small Bus. J. 16, 36-57. http://dx.doi.org/10. $1177 / 0266242697161003$.

Bürer, M.J., Wüstenhagen, R., 2009. Which renewable energy policy is a venture capitalist's best friend? Empirical evidence from a survey of international cleantech investors. Energy Policy 37, 4997-5006. http://dx.doi.org/10.1016/j.enpol.2009.06. 071.

Busenitz, L.W., Fiet, J.O., Moesel, D.D., 2005. Signaling in venture capitalist-new venture team funding decisions: does it indicate long-term venture outcomes? Entrep. Theory Pract. 29, 1-12. http://dx.doi.org/10.1111/j.1540-6520.2005.00066.x.

Caliendo, M., Fossen, F.M., Kritikos, A.S., 2009. Risk attitudes of nascent entrepreneurs-new evidence from an experimentally validated survey. Small Bus. Econ. 32, 153-167. http://dx.doi.org/10.1007/s11187-007-9078-6.

Casamatta, C., 2003. Financing and advising: optimal financial contracts with venture capitalists. J. Financ. 58, 2059-2085. http://dx.doi.org/10.1111/1540-6261.00597.

Cassar, G., 2004. The financing of business start-ups. J. Bus. Ventur. 19, 261-283.

Chassot, S., Hampl, N., Wüstenhagen, R., 2014. When energy policy meets free-market capitalists: the moderating influence of worldviews on risk perception and renewable energy investment decisions. Energy Res. Soc. Sci. 3, 143-151. http://dx.doi.org/10. 1016/j.erss.2014.07.013.

Chen, X.-P., Yao, X., Kotha, S., 2009. Entrepreneur passion and preparedness in business 
plan presentations: a persuasion analysis of venture capitalists' funding decisions. Acad. Manag. J. 52, 199-214.

Cohen, B., Winn, M.I., 2007. Market imperfections, opportunity and sustainable entrepreneurship. J. Bus. Ventur. 22, 29-49. http://dx.doi.org/10.1016/j.jbusvent. 2004.12.001.

Cohen, J., Cohen, P., West, S.G., Aiken, L.S., 2009. Applied Multiple Regression Correlation Analysis for the Behavioral Sciences, 3rd ed. L. Erlbaum Associates, Mahwah, N.J.

Colombo, M.G., Grilli, L., 2010. On growth drivers of high-tech start-ups: exploring the role of founders' human capital and venture capital. J. Bus. Ventur. 25, 610-626. http://dx.doi.org/10.1016/j.jbusvent.2009.01.005.

Connelly, B.L., Certo, S.T., Ireland, R.D., Reutzel, C.R., 2011. Signaling theory: a review and assessment. J. Manag. 37, 39-67. http://dx.doi.org/10.1177/ 0149206310388419.

Cowling, M., Liu, W., Minniti, M., Zhang, N., 2016. UK credit and discouragement during the GFC. Small Bus. Econ. 47, 1049-1074. http://dx.doi.org/10.1007/s11187-0169745-6.

Cressy, R., 2002. Funding gaps: a symposium. Econ. J. 112, F1-F16.

Creswell, J.W., Clark, V.L.P., 2010. Designing and Conducting Mixed Methods Research. SAGE, Thounsand Oaks, CA.

Criscuolo, C., Menon, C., 2015. Environmental policies and risk finance in the green sector: cross-country evidence. Energy Policy 83, 38-56. http://dx.doi.org/10.1016/ j.enpol.2015.03.023.

Demirel, P., Parris, S., 2015. Access to finance for innovators in the UK's environmental sector. Tech. Anal. Strat. Manag. 27, 782-808. http://dx.doi.org/10.1080/09537325. 2015.1019849.

Dimov, D., de Holan, P.M., Milanov, H., 2012. Learning patterns in venture capital investing in new industries. Ind. Corp. Chang. 21, 1389-1426. http://dx.doi.org/10. 1093/icc/dts010.

Eckhardt, J.T., Shane, S., Delmar, F., 2006. Multistage selection and the financing of new ventures. Manag. Sci. 52, 220-232. http://dx.doi.org/10.1287/mnsc.1050.0478.

Eisenhardt, K.M., 1989. Building theories from case study research. Acad. Manag. Rev. $14,532-550$

Foxon, T.J., Köhler, J., Oughton, C., 2008. Innovation for a Low Carbon Economy: Economic, Institutional and Management Approaches. Edward Elgar Publishing, Cheltenham, UK.

Franke, N., Gruber, M., Harhoff, D., Henkel, J., 2006. What you are is what you likesimilarity biases in venture capitalists' evaluations of start-up teams. J. Bus. Ventur. $21,802-826$.

Fried, V.H., Hisrich, R.D., 1994. Toward a model of venture capital investment decision making. Financ. Manag. 23, 28-37.

Ghosh, S., Nanda, R., 2010. Venture Capital Investment in the Clean Energy Sector (SSRN Scholarly Paper No. ID 1669445). Social Science Research Network, Rochester, NY.

Giudici, G., Paleari, S., 2000. The provision of finance to innovation: a survey conducted among Italian technology-based small firms. Small Bus. Econ. 14, 37-53.

Gompers, P.A., 1995. Optimal investment, monitoring, and the staging of venture capital. J. Financ. 50, 1461-1489. http://dx.doi.org/10.2307/2329323.

Gompers, P.A., Lerner, J., 2001. The venture capital revolution. J. Econ. Perspect. 15, 145-168.

Gorman, M., Sahlman, W.A., 1989. What do venture capitalists do? J. Bus. Ventur. 4, 231-248. http://dx.doi.org/10.1016/0883-9026(89)90014-1.

Granovetter, M.S., 1973. The strength of weak ties. Am. J. Sociol. 78, 1360-1380.

Haegeman, K., Marinelli, E., Scapolo, F., Ricci, A., Sokolov, A., 2013. Quantitative and qualitative approaches in Future-oriented Technology Analysis (FTA): from combination to integration? In: Technol. Forecast. Soc. Change, Future-Oriented Technol. Analysis 80. pp. 386-397. http://dx.doi.org/10.1016/j.techfore.2012.10.002.

Hall, B.H., 2002. The Financing of Research and Development (Working Paper No. 8773). National Bureau of Economic Research, Cambridge, Mass.

Hall, P.A., 2015. Varieties of capitalism. In: Scott, R.A., Buchmann, M.C., Kosslyn, S.M. (Eds.), Emerging Trends in the Social and Behavioral Sciences. John Wiley \& Sons, Inc., Hoboken, NJ, USA.

Hall, P.A., Soskice, D., 2001. Varieties of Capitalism: The Institutional Foundations of Comparative Advantage. OUP Oxford.

Hall, S., Foxon, T.J., Bolton, R., 2016. Financing the civic energy sector: how financial institutions affect ownership models in Germany and the United Kingdom. Energy Res. Soc. Sci. 12, 5-15. http://dx.doi.org/10.1016/j.erss.2015.11.004.

Harhoff, D., 2011. The role of patents and licenses in securing external finance for innovation. Handb. Res. Innov. Entrep. 55-73.

Hellmann, T., Puri, M., 2000. The interaction between product market and financing strategy: The role of venture capital. Rev. Financ. Stud. 13, 959-984. http://dx.doi. org/10.1093/rfs/13.4.959.

Hellmann, T., Puri, M., 2002. Venture capital and the professionalization of start-up firms: empirical evidence. J. Financ. 57, 169-197. http://dx.doi.org/10.1111/15406261.00419.

Higashide, H., Birley, S., 2002. The consequences of conflict between the venture capitalist and the entrepreneurial team in the United Kingdom from the perspective of the venture capitalist. J. Bus. Ventur. 17, 59.

Hirsch-Kreinsen, H., 2011. Financial market and technological innovation. Ind. Innov. 18, 351-368. http://dx.doi.org/10.1080/13662716.2011.573954.

Hockerts, K., Wüstenhagen, R., 2010. Greening Goliaths versus emerging Davids - theorizing about the role of incumbents and new entrants in sustainable entrepreneurship. J. Bus. Ventur. 25, 481-492. http://dx.doi.org/10.1016/j.jbusvent.2009.07.005.

Hopkins, M.M., Crane, P.A., Nightingale, P., Baden-Fuller, C., 2013. Buying big into biotech: scale, financing, and the industrial dynamics of UK biotech, 1980-2009. Ind. Corp. Chang. 22, 903-952. http://dx.doi.org/10.1093/icc/dtt022.

Hsu, D.H., 2006. Venture capitalists and cooperative start-up commercialization strategy.
Manag. Sci. 52, 204-219. http://dx.doi.org/10.1287/mnsc.1050.0480.

Hsu, D.H., 2007. Experienced entrepreneurial founders, organizational capital, and ven ture capital funding. Res. Policy 36, 722-741. http://dx.doi.org/10.1016/j.respol. 2007.02.022.

InvestEurope, 2016. InvestEurope PEREP Analytics [WWW Document]. In: InvestEurope Res, (URL https://www.investeurope.eu/research/).

Iyer, G., Hultman, N., Eom, J., McJeon, H., Patel, P., Clarke, L., 2015. Diffusion of lowcarbon technologies and the feasibility of long-term climate targets. Technol. Forecast. Soc. Chang. 90, 103-118. http://dx.doi.org/10.1016/j.techfore.2013.08. 025.

Jick, T.D., 1979. Mixing qualitative and quantitative methods: triangulation in action. Adm. Sci. Q. 24, 602-611. http://dx.doi.org/10.2307/2392366.

Kenney, M., Hargadon, A., 2012. Misguided policy? Calif. Manag. Rev. 54, 118-139. http://dx.doi.org/10.1525/cmr.2012.54.2.118.

Kenney, M., Hargadon, A., 2014. Venture capital and clean technology. In: Huberty, M., Zysman, J. (Eds.), Can Green Sustain Growth? From the Rhetoric to the Reality of Sustainable Prosperity. Stanford University Press, Stanford.

Kleer, R., 2010. Government R \& D subsidies as a signal for private investors. Res. Policy 39, 1361-1374. http://dx.doi.org/10.1016/j.respol.2010.08.001.

Lerner, J., Tåg, J., 2013. Institutions and venture capital. Ind. Corp. Chang. 22, 153-182. http://dx.doi.org/10.1093/icc/dts050.

Li, Y., Zahra, S.A., 2012. Formal institutions, culture, and venture capital activity: a crosscountry analysis. J. Bus. Ventur. 27, 95-111. http://dx.doi.org/10.1016/j.jbusvent. 2010.06.003.

Lüthi, S., Prässler, T., 2011. Analyzing policy support instruments and regulatory risk factors for wind energy deployment-a developers' perspective. Energy Policy 39, 4876-4892. http://dx.doi.org/10.1016/j.enpol.2011.06.029.

Lüthi, S., Wüstenhagen, R., 2012. The price of policy risk - empirical insights from choice experiments with European photovoltaic project developers. Energy Econ. 34, 1001-1011. http://dx.doi.org/10.1016/j.eneco.2011.08.007.

Marcus, A., Malen, J., Ellis, S., 2013. The promise and pitfalls of venture capital as an asset class for clean energy investment research questions for organization and natural environment scholars. Organ. Environ. 26, 31-60. http://dx.doi.org/10.1177/ 1086026612474956.

Mazzucato, M., 2013. The Entrepreneurial State: Debunking Public vs. Private Sector Myths. Anthem Press, London, New York.

Mazzucato, M., Semieniuk, G., 2017. Financing renewable energy: who is financing what and why it matters. Technol. Forecast. Soc. Chang. http://dx.doi.org/10.1016/j. techfore.2017.05.021.

McCrone, A., Moslener, U., d'Estais, F., Usher, E., Grüning, C., 2016. Global Trends in Renewable Energy Investment 2016. FS UNEP Centre, Frankfurt am Main.

Migendt, M., Polzin, F., Schock, F., Täube, F.A., von Flotow, P., 2017. Beyond venture capital: an exploratory study of the finance-innovation-policy nexus in cleantech. Ind. Corp. Chang. http://dx.doi.org/10.1093/icc/dtx014.

Mina, A., Lahr, H., Hughes, A., 2013. The demand and supply of external finance for innovative firms. Ind. Corp. Chang. 22, 869-901. http://dx.doi.org/10.1093/icc/ dtt020.

Moran-Ellis, J., Alexander, V.D., Cronin, A., Dickinson, M., Fielding, J., Sleney, J., Thomas, H., 2006. Triangulation and integration: processes, claims and implications. Qual. Res. 6, 45-59. http://dx.doi.org/10.1177/1468794106058870.

Mrkajic, B., Murtinu, S., Scalera, V.G., 2016. Is Green the New Gold? Venture Capital and Green Entrepreneurship (SSRN Scholarly Paper No. ID 2757653). Social Science Research Network, Rochester, NY.

Murnieks, C.Y., Haynie, J.M., Wiltbank, R.E., Harting, T., 2011. 'I Like How You Think': similarity as an interaction bias in the investor-entrepreneur dyad. J. Manag. Stud. 48, 1533-1561. http://dx.doi.org/10.1111/j.1467-6486.2010.00992.x.

Nightingale, P., Murray, G., Cowling, M., Baden-Fuller, C., Mason, C., Siepel, J., Hopkins, M., Dannreuther, C., 2009. From Funding Gaps to Thin Markets: UK Government Support for Early-stage Venture Capital. Nesta, London.

NVCA, 2016. Clean technology investment by year [WWW Document]. URL. http://nvca. org/research/research-resources/.

OECD, 2015. New Approaches to SME and Entrepreneurship Financing: Broadening the Range of Instruments. OECD, Paris.

OECD, 2017. OECD Gross-Domestic Product Statistics [WWW Document]. URL. https:// data.oecd.org/gdp/gross-domestic-product-gdp.htm.

Olsen, W., 2004. Triangulation in social research: qualitative and quantitative methods can really be mixed. Dev. Sociol. 20, 103-118.

Parhankangas, A., Hellström, T., 2007. How experience and perceptions shape risky behaviour: evidence from the venture capital industry. Ventur. Cap. 9, 183-205. http:// dx.doi.org/10.1080/13691060701324478.

Patton, M.Q., 2002. Qualitative Research and Evaluation Methods. SAGE, Thousand Oaks, CA.

Peneder, M., 2010. The impact of venture capital on innovation behaviour and firm growth. Ventur. Cap. Int. J. Entrep. Financ. 12, 83-107.

Petersen, M.A., Rajan, R.G., 2002. Does distance still matter? The information revolution in small business lending. J. Financ. 57, 2533-2570. http://dx.doi.org/10.1111/ 1540-6261.00505.

Petkova, A.P., Wadhwa, A., Yao, X., Jain, S., 2014. Reputation and decision making under ambiguity: a study of US venture capital firms' investments in the emerging clean energy sector. Acad. Manag. J. 57, 422-448.

Petty, J.S., Gruber, M., 2011. "In pursuit of the real deal": a longitudinal study of VC decision making. J. Bus. Ventur. 26, 172-188. http://dx.doi.org/10.1016/j.jbusvent. 2009.07.002.

Podsakoff, P.M., MacKenzie, S.B., Lee, J.-Y., Podsakoff, N.P., 2003. Common method biases in behavioral research: a critical review of the literature and recommended remedies. J. Appl. Psychol. 88, 879. 
Polzin, F., 2017. Mobilizing private finance for low-carbon innovation - a systematic review of barriers and solutions. Renew. Sust. Energ. Rev. 77, 525-535. http://dx. doi.org/10.1016/j.rser.2017.04.007.

Polzin, F., von Flotow, P., Klerkx, L., 2016. Addressing barriers to eco-innovation: exploring the finance mobilisation functions of institutional innovation intermediaries. Technol. Forecast. Soc. Chang. 103, 34-46. http://dx.doi.org/10.1016/j.techfore. 2015.10.001.

Polzin, F., Sanders, M., Stavlöt, U., 2017. Mobilising early stage investments for an innovation-led sustainability transition. In: Walker, T., Kibsey, S., Crichton, R. (Eds.), Designing a Sustainable Financial System: Development Goals and Socio-ecological Responsibility. Palgrave Macmillan, New York.

Riding, A.L., 2008. Business angels and love money investors: segments of the informal market for risk capital. Ventur. Cap. Int. J. Entrep. Financ. 10, 355-369.

Riding, A.L., Short, D.M., 1987. Some investor and entrepreneur perspectives on the informal market for risk capital. J. Small Bus. Entrep. 5, 19-30. http://dx.doi.org/10. 1080/08276331.1987.10600291.

Ruef, M., Aldrich, H.E., Carter, N.M., 2003. The structure of founding teams: homophily, strong ties, and isolation among U.S. Entrepreneurs. Am. Sociol. Rev. 68, 195-222. http://dx.doi.org/10.2307/1519766.

Sahlman, W.A., 1990. The structure and governance of venture-capital organizations. J. Financ. Econ. 27, 473-521. http://dx.doi.org/10.1016/0304-405X(90)90065-8.

Sanders, M., Welters, R., 2013. Recruitment in recovery. In: Meijers, H., van Veen, T. (Eds.), Liber Amicorum for Prof. J. Muysken. Maastricht University Press, Maastricht.

Sanders, M., Fuss, S., Engelen, P.-J., 2013. Mobilizing private funds for carbon capture and storage: an exploratory field study in The Netherlands. Int. J. Greenh. Gas Control 19, 595-605. http://dx.doi.org/10.1016/j.ijggc.2013.09.015.

Seawright, J., Gerring, J., 2008. Case selection techniques in case study research. Polit. Res. Q. 61, 294-308. http://dx.doi.org/10.1177/1065912907313077.

Shepherd, D.A., Zacharakis, A., 2001. The venture capitalist-entrepreneur relationship: control, trust and confidence in co-operative behaviour. Ventur. Cap. Int. J. Entrep. Financ. 3, 129-149.

Söderblom, A., 2012. The Current State of the Venture Capital industry. Entreprenörskapsforum, Stockholm.

Sørensen, M., 2007. How smart is smart money? A two-sided matching model of venture capital. J. Financ. 62, 2725-2762. http://dx.doi.org/10.1111/j.1540-6261.2007. 01291.x.

Spence, M., 1973. Job market signaling. Q. J. Econ. 87, 355-374. http://dx.doi.org/10 $2307 / 1882010$.

Stein, J.C., 2002. Information production and capital allocation: decentralized versus hierarchical firms. J. Financ. 57, 1891-1921. http://dx.doi.org/10.1111/0022-1082.
00483.

Stucki, T., 2014. Success of start-up firms: the role of financial constraints. Ind. Corp. Chang. 23, 25-64. http://dx.doi.org/10.1093/icc/dtt008.

Tapio, P., Paloniemi, R., Varho, V., Vinnari, M., 2011. The unholy marriage? Integrating qualitative and quantitative information in Delphi processes. Technol. Forecast. Soc. Chang. 78, 1616-1628. http://dx.doi.org/10.1016/j.techfore.2011.03.016.

van den Bergh, J.C.J.M., 2013. Environmental and climate innovation: limitations, policies and prices. Technol. Forecast. Soc. Chang. 80, 11-23. http://dx.doi.org/10. 1016/j.techfore.2012.08.004.

Wüstenhagen, R., Teppo, T., 2006. Do venture capitalists really invest in good industries? Risk-return perceptions and path dependence in the emerging European energy VC market. Int. J. Technol. Manag. 34, 63-87.

Wüstenhagen, R., Wuebker, R., 2011. The Handbook of Research on Energy Entrepreneurship. Edward Elgar Publishing, Cheltenham.

Yin, R.K., 2009. Case Study Research: Design and Methods. SAGE, Thousand Oaks, CA.

Friedemann Polzin is an Assistant Professor at Utrecht School of Economics (U.S.E.), Sustainable Finance Lab in Utrecht, the Netherlands and also affiliated with the Sustainable Business Institute (SBI) in Oestrich-Winkel, Germany. He holds a PhD in Business Economics from EBS Business School and a Diploma (equivalent MSc) in Business Administration from the University of Jena. His research investigates the financing of eco- innovation and corresponding structures (such as alternative forms of finance) as well as the political/regulatory environment required for a transition towards a green economy.

Ulrika Stavlöt is research director at Forum for Reforms, Entrepreneurship and Sustainability (FORES). Ulrika has a PhD in economics from the Institute for International Economic Studies (IIES) at Stockholm University. Before joining FORES she worked as a senior researcher at the Swedish Institute for European Policy Studies and as a consultant for the OECD Development Centre. Ulrika's research focuses on international trade and macroeconomics. She is also working on various topics related to environmental policy.

Mark Sanders is an Associate Professor at Utrecht School of Economics (U.S.E.) in Utrecht, the Netherlands. He researches and teaches topics that connect entrepreneurship, innovation and the transition towards more sustainable economic growth. His methods are both empirical and theoretical and his teaching is both within the economics department and in courses at the faculty of geosciences and sciences. Mark is also a member of the Sustainable Finance Lab that aims to make financial markets contribute to this transition. 